\title{
Migratory Tropical Cyclones in the South China Sea Modulated by Intraseasonal Oscillations and Climatological Circulations
}

\author{
JAU-MING CHEN \\ Department of Maritime Information and Technology, National Kaohsiung University of Science and Technology, \\ Kaohsiung, Taiwan \\ CHING-HSUAN WU \\ Department of Atmospheric Science, National Taiwan University, Taipei, Taiwan \\ JIANYUN GAO \\ Fujian Institute of Meteorological Sciences, Fuzhou, China \\ Pei-Hsuan Chung \\ Department of History and Geography, University of Taipei, Taipei, Taiwan \\ CHUNG-Hsiung SuI \\ Department of Atmospheric Science, National Taiwan University, Taipei, Taiwan
}

(Manuscript received 3 December 2018, in final form 28 June 2019)

\begin{abstract}
This study focuses on the migratory tropical cyclones (TCs) that form in the western North Pacific (WNP) and move into the South China Sea (SCS). Their movements are found to be modulated differently by intraseasonal oscillations (ISOs) and climatological circulations through the TC-active months. The modulating processes of climatological circulations vary from a westward intensifying western Pacific subtropical high (WPSH) in July and August to a southeastward extending monsoon trough (MT) in September, and a strengthening equatorial trough (ET) in October and November. In July and August, enhanced tropical ISO convections in the SCS are accompanied by a 30-60-day anomalous anticyclone to the northeast of the SCS. The migratory TCs move along the southern peripheries of this anomalous anticyclone and the WPSH into the SCS. In September, enhanced ISO convections in the SCS coincide with a meridional 30-60-day circulation pair with an anomalous anticyclone to the north of $20^{\circ} \mathrm{N}$ and an anomalous cyclone to the south. TCs move in between this meridional 30-60-day circulation pair and the northern periphery of the MT toward the SCS. In October and November, enhanced ISO convections in the SCS and WNP coexist with an overlying 30-60-day anomalous cyclone and an intensified ET. The migratory TCs move along the northern sections of this 30-60-day anomalous cyclone and the ET toward the SCS. With a different track, TCs recurving northward from the tropical WNP into the region east of Taiwan are modulated by completely different variability features of the 30-60-day ISO and climatological circulations.
\end{abstract}

\section{Introduction}

Weather and climate phenomena over the western North Pacific (WNP) and South China Sea (SCS) are significantly influenced by the Asian monsoon circulation and tropical cyclone (TC) activity. Two climatological features of the Asian monsoon circulation are the

Corresponding author: Chung-Hsiung Sui, sui@as.ntu.edu.tw western Pacific subtropical high (WPSH) and monsoon trough (MT). Both the WPSH and MT move northward in June-July, reach the northernmost locations in August-September, and shift southward in OctoberNovember (e.g., Ding 1994; Lander 1996; Wu et al. 2012). Their spatial migrations result in different phases of the Asian monsoon. The first one is the SCS monsoon with an onset around mid-May when the WPSH retreats eastward away from the SCS (e.g., Chang and Chen 
1995; Chen and Chen 1995; Wang and Fan 1999). It is followed by an East Asian summer monsoon in June and July in association with the northward jumps of the WPSH (e.g., Chen 1994; Wu 2002; Su and Xue 2011). The last one is the WNP summer monsoon in August when the WPSH is in its northernmost position (e.g., Wang and LinHo 2002). After summer, both the WPSH and MT displace southward, signifying the end of the summer monsoon. The trough in October-November shifts to the south of $10^{\circ}-15^{\circ} \mathrm{N}$ and is referred to as the equatorial trough (ET; Malkus 1962). Climatologically, TCs tend to form in a favorable environment of large vorticity provided by an MT or ET. Their maximum genesis locations in the WNP follow the meridional migrations of the MT, progressing northward in summer and southward in fall (e.g., Chen et al. 2006; Chen et al. 2017). In the SCS, TC genesis mainly gathers in the northern basin during summer in accordance with the appearance of an overlying MT and displaces to the southern basin during fall in company with the southward shift of the trough (e.g., Wang et al. 2007). The above results indicate the existence of a close interaction between the climatological circulations and TC activity.

The climatological circulations mentioned above contain interannual and interdecadal variability that all influence TC genesis and evolution (e.g., Ho et al. 2004; Chen et al. 2006; Sui et al. 2007; Wu and Wang 2015). It has also been shown that circulations of the SCS, East Asian, and WNP monsoons all exhibit noticeable intraseasonal oscillations (ISOs) (e.g., Chen and Chen 1995; Hsu 2005; Li and Wang 2005; Ding 2007). TC characteristics (genesis frequency, genesis location, moving track) in the WNP and SCS are under the evident influence of intraseasonal variability of the WPSH and MT (e.g., Harr and Elsberry 1991; Lander 1996; Chan 2000; Ho et al. 2004; Nakazawa and Rajendran 2007). Compared with the interannual- and interdecadalscale influence, the intraseasonal-scale influence on TC activities is more efficient in terms of TC genesis probability (e.g., Chen et al. 2018a). In general, a westwardintensified WPSH and a weakened MT are accompanied by strong easterly flows that tend to steer TCs with a westward/northwestward track, while an eastwardretreated WPSH and a deepened MT tend to concur with the recurving TCs (e.g., Chen et al. 2009; Ko and Hsu 2009). An enhanced MT may occur concurrently with a northwestward propagation of a submonthly wavelike pattern to provide a large-scale flow environment for most TCs (about 70\%) embedded within the flow to have a recurving track (e.g., Ko and Hsu 2006). In the eastern section of the WNP (east of $150^{\circ} \mathrm{E}$ ), a convectively enhanced ISO phase together with an eastward extending MT tends to increase TC genesis in a region south of $15^{\circ} \mathrm{N}$ (e.g., Kim et al. 2008). Vorticity of the intraseasonal circulation is found to be a key factor affecting TC genesis in the subtropical region during JulySeptember (e.g., Huang et al. 2011), indicating the importance of intraseasonal circulation anomalies in modulating TC activity.

ISOs contain two major modes that occur in 10-24and 30-60-day frequency bands (e.g., Hartmann et al. 1992; Chen et al. 2000; Mao and Chan 2005; Ding 2007). The general ISO modulations on TC activity appear as TC genesis increasing (decreasing) in a convectively enhanced (suppressed) ISO phase (e.g., Hall et al. 2001; Barrett and Leslie 2009; Klotzbach 2014).The synoptic disturbances tend to extract (lose) eddy kinetic energy from (to) ISOs during the active (inactive) phase (Hsu et al. 2011). Active ISO phases act to facilitate the occurrence of multiple TC events (Gao and Li 2011), while stronger ISO intensity matches increased multiple TC events on an interannual time scale (Gao and Li 2012). These results indicate that the development of synopticscale disturbances can be effectively modulated by ISOs (Li et al. 2014). After formation, TCs in the WNP may cluster around the center of a propagating 10-24-day cyclonic anomaly to move westward/northwestward along a large-scale favorable environment provided by a northwesterly-southeasterly elongated 30-60-day cyclonic anomaly (e.g., Liebmann et al. 1994; Chen et al. 2018b). TCs tend to intensify quickly in a favorable environment provided by the active phase of the 10-24-day ISO (Zhou et al. 2018). Kim et al. (2008) demonstrated that the dense area of TC tracks displaces zonally in the WNP in accordance with locations of the convective center of the 30-60-day ISO. Li and Zhou (2013) showed that during convective (nonconvective) phases of the 10-24- and 30-60-day ISOs, the majority of TCs in the WNP exhibit a westward/northwestward (recurving) track. The ISO modulation on TC genesis is enhanced during an El Niño year (Li et al. 2012) and is stronger in fall than summer (Choi and Ha 2018). In the SCS, increased rainfall at Hainan Island during SeptemberOctober was found to be mainly attributable to enhanced TC activity modulated by ISOs (Feng et al. 2013). The above results indicate that ISO circulations can effectively modulate TC genesis, movement, and rainfall.

One major TC track in the WNP moves from the WNP into the SCS (e.g., Camargo et al. 2007; Chu et al. 2010). Chen et al. (2017) illustrated that the chance for a WNP TC entering the SCS varies seasonally, being highest (lowest) in October-November (AugustSeptember) when the WPSH and MT are located in a more southern (northern) position. They also showed that in the TC-active season the migration of the WNP 
TCs into the SCS is commonly facilitated by anomalous easterly/southeasterly flows sandwiched by a pair of total ISO (10-90 day) circulations with an anomalous anticyclone to the north and an anomalous cyclone to the south. The above results suggest that TC movements from the WNP into the SCS can be modulated by ISOs and variability of the WPSH and MT. Modulations of the large-scale circulations on TC movements into the SCS have been studied on interannual and interdecadal time scales (Goh and Chan 2010; Tan et al. 2019). However, ISO modulation on TC movements from the WNP $\left(120^{\circ} \mathrm{E}-180^{\circ}, 0^{\circ}-40^{\circ} \mathrm{N}\right)$ into the SCS $\left(108^{\circ}-120^{\circ} \mathrm{E}\right.$, $\left.5^{\circ}-22^{\circ} \mathrm{N}\right)$ and its associations with the climatological circulations (WPSH, MT, and ET) have not been comprehensively studied. The variability of such modulating processes through the active TC season needs to be specifically examined. Moreover, the variability of ISO modulations on different types of TC tracks also needs to be delineated. These issues are the focus of this study with the expectation that the results could help clarify the relationships between TC movements, ISO anomalies, and variability of the climatological circulations. Understanding these relationships may offer improved TC forecasting capability via monitoring variability features of key ISO and climatological circulations.

\section{Data}

Three datasets are used in this study. The circulations are depicted by daily European Center for MediumRange Weather Forecasts (ECMWF) ERA-Interim reanalysis data (e.g., Dee et al. 2011). This dataset has a spatial resolution on a $0.75^{\circ} \times 0.75^{\circ}$ grid. Its winds, streamfunction, and geopotential heights are used to depict variability features of the climatological circulations and ISO anomalies. TC activity is portrayed by the 6-h best track dataset obtained from the Joint Typhoon Warning Center (JTWC). The JTWC dataset is used to delineate genesis locations, formation numbers, movement tracks, and passage frequency of TCs in the WNP. The convection associated with ISO anomalies is illustrated by the National Oceanic and Atmospheric Administration (NOAA) daily outgoing longwave radiation $(\mathrm{OLR})$ data with a $2.5^{\circ} \times 2.5^{\circ}$ resolution $(\mathrm{e} . \mathrm{g}$., Liebmann and Smith 1996). The analysis period spans from 1979 to 2015.

\section{Climatological features of migratory TCs and circulations}

In terms of TC genesis, a TC must reach the intensity of a tropical storm. Further, the first records of the JTWC's best track data that have maximum sustained

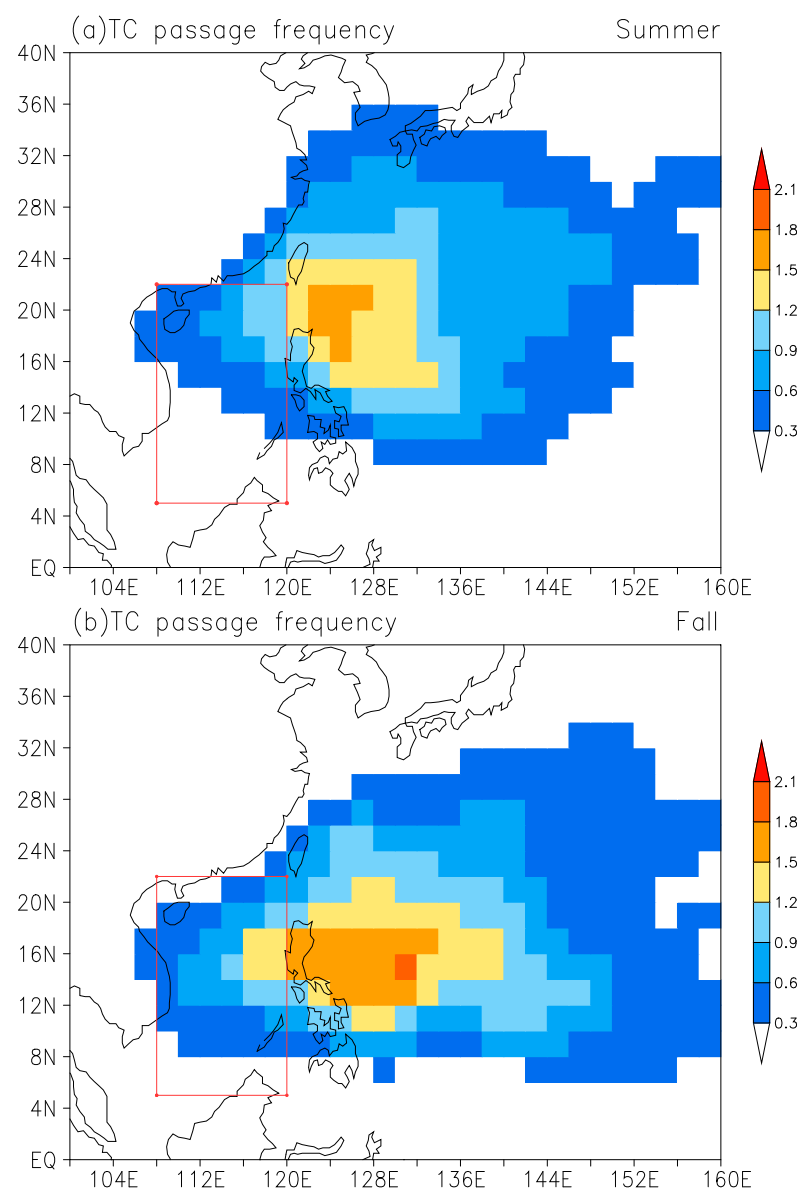

FIG. 1. The passage frequency accumulated for (a) summer and (b) fall for TCs forming in the WNP during the period 1979-2010 using the 6-h JTWC best track data. The red box indicates the SCS domain $\left(108^{\circ}-120^{\circ} \mathrm{E}, 5^{\circ}-22^{\circ} \mathrm{N}\right)$.

wind speeds greater than or equal to $34 \mathrm{kt}(1 \mathrm{kt} \approx$ $0.51 \mathrm{~m} \mathrm{~s}^{-1}$ ) are used to define the timing and position of TC genesis. To depict the spatial features of TC movement from the WNP into the SCS, passage frequency patterns accumulated for summer (JJA) and fall (SON) throughout the period 1979-2015 are shown in Fig. 1. This passage frequency is represented by the total appearance number of TCs in every $2^{\circ} \times 2^{\circ}$ box summed from the 6-h JTWC best track data. Only TCs forming in the WNP $\left(120^{\circ} \mathrm{E}-180^{\circ}, 0^{\circ}-40^{\circ} \mathrm{N}\right)$ are counted in this frequency. The frequency pattern is smoothed with the following method: $f_{x, y}=1 / 4 \times\left[1 \times\left(f_{x, y}\right)+0.5 \times\right.$ $\left(f_{x-1, y}+f_{x+1, y}+f_{x, y-1}+f_{x, y+1}\right)+0.25 \times\left(f_{x-1, y-1}+\right.$ $\left.\left.f_{x-1, y+1}+f_{x+1, y-1}+f_{x+1, y+1}\right)\right]$, where subscripts $x$ and $y$ denote zonal and meridional coordinates, respectively. Major TC activity (indicated by passage frequency $\geq$ 1.2) occurs in the $120^{\circ}-132^{\circ} \mathrm{E}, 14^{\circ}-24^{\circ} \mathrm{N}$ region during summer and in the $120^{\circ}-140^{\circ} \mathrm{E}, 12^{\circ}-20^{\circ} \mathrm{N}$ region during fall. TC movements in fall are more zonal than that in 

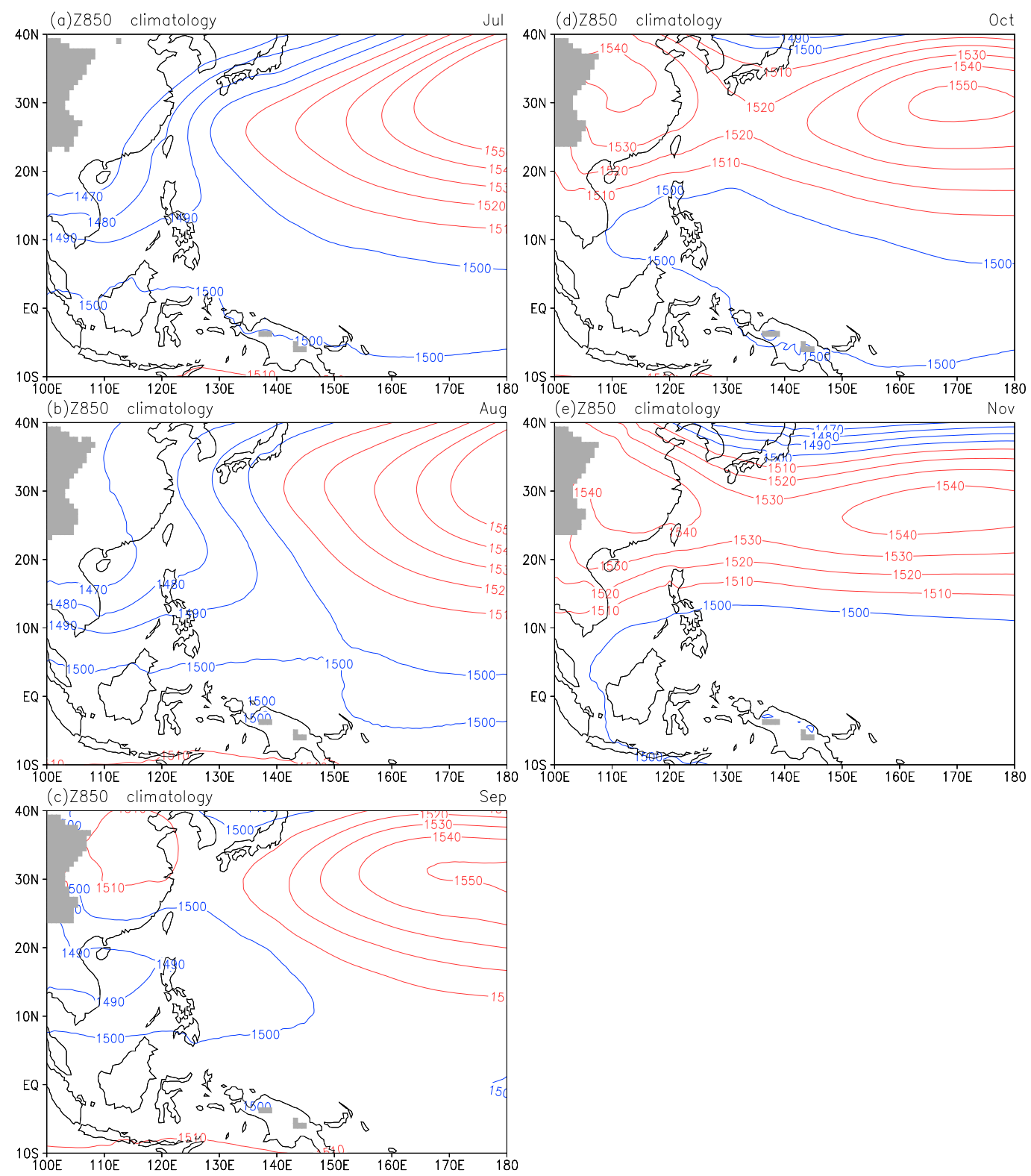

FIG. 2. The 1979-2015 climatological patterns of 850-hPa geopotential height (Z850) for (a) July, (b) August, (c) September, (d) October, and (e) November.

summer. The migration of the WNP TCs into the SCS is also larger in frequency and in a more southern region during fall than summer, as indicated by the existence of a frequency center in the $116^{\circ}-120^{\circ} \mathrm{E}, 14^{\circ}-18^{\circ} \mathrm{N}$ region during fall. The more zonal and more southern tracks of the migratory TCs during fall than summer are related to seasonal distributions of the background circulations that are shown by the climatological $850-\mathrm{hPa}$ geopotential height (Z850) in Fig. 2. During July and August (Figs. 2a,b), the WPSH displaces northward, while the MT extends southeastward. This pattern favors northward/northwestward TC movements toward eastern China and Japan. In September (Fig. 2c), the WPSH extends westward with a less southeastward extension of the MT. In October and November (Figs. 2d,e), the WPSH shifts southward to elongate across East Asia and the WNP, while the ET extends across the tropical Pacific. Under these conditions, the extended ET across the tropical Pacific facilitates TC movement along the ET westward in a more southern region, while the zonally elongating WPSH hinders the northward movement of TCs. 


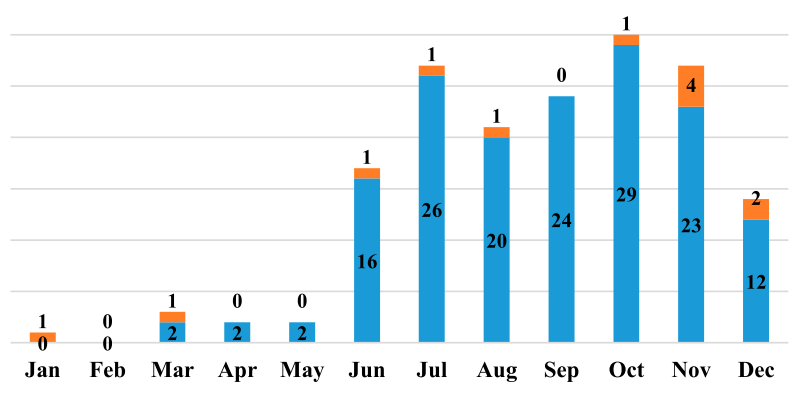

FIG. 3. Numbers of the migratory TCs forming in the $120^{\circ}-150^{\circ} \mathrm{E}$ (blue bars) and $150^{\circ} \mathrm{E}-180^{\circ}$ (orange bars) regions for each calendar month accumulated for the period 1979-2015.

Following Chen et al. (2017), the SCS domain is defined as the $108^{\circ}-120^{\circ} \mathrm{E}, 5^{\circ}-22^{\circ} \mathrm{N}$ region, which is an area under evident TC influence (indicated by the red box in Fig. 1). TCs forming in the WNP and later moving into the SCS domain are defined as the migratory TCs. These TCs must reach tropical storm intensity or greater in both the WNP and SCS regions. During the period 1979-2015, the accumulated number of the migratory TCs with a formative location to the east (orange bar) or west (blue bar) of $150^{\circ} \mathrm{E}$ for each calendar month is illustrated in Fig. 3. It shows clear seasonal variability and spatial distribution. The total number is around $0-3$ in the inactive TC season from January to May. This number increases from June (17) to July (27) and decreases in August (21) and September (24). The number is maximal in October (30) and November (27) and decreases rapidly in December (14). There are a total of 168 migratory TCs over 37 years (1979-2015) with an average of 4.5 migratory TCs per year. In the active TC season from July to November, 122 out of 129 migratory TCs $(\sim 95 \%)$ form in the $120^{\circ}-150^{\circ} \mathrm{E}$ region, while only 7 migratory TCs $(\sim 5 \%)$ form in the region east of $150^{\circ} \mathrm{E}$. The majority of the migratory TCs show a spatial preference in genesis location closer to the SCS. To have more coherent spatial features, only the migratory TCs forming in the $120^{\circ}-150^{\circ} \mathrm{E}$ region are included in later analyses. Figure 3 shows that the number of the migratory TCs forming in the $120^{\circ}-150^{\circ} \mathrm{E}$ region is more than 20 from July to November and less than 20 in June and December. The active season of the migratory TCs is thus defined as the period from July to November; June and December are excluded. This active season of JulyNovember has been used in analyzing the WNP TC activity by $\mathrm{Wu}$ et al. (2012) and $\mathrm{Wu}$ and Takahashi (2018). However, it is different from the peak TC season of June-October analyzed in some previous studies (Kim. et al. 2012; Li et al. 2017; Tu and Chen 2019). Our analyses also reveal that the ratio of the migratory TCs to total TCs forming in the $120^{\circ}-150^{\circ} \mathrm{E}$ region decreases
TABLE 1. The mean genesis locations and mean latitudes entering the SCS (across $120^{\circ} \mathrm{E}$ longitude) for the migratory TCs from July to November.

\begin{tabular}{lcc}
\hline \hline \multicolumn{1}{c}{ Month } & Mean genesis location & $\begin{array}{c}\text { Mean latitude } \\
\text { entering the SCS }\end{array}$ \\
\hline July & $14.5^{\circ} \mathrm{N}, 131.8^{\circ} \mathrm{E}$ & $18.1^{\circ} \mathrm{N}$ \\
August & $15.8^{\circ} \mathrm{N}, 131.9^{\circ} \mathrm{E}$ & $18.3^{\circ} \mathrm{N}$ \\
September & $15.5^{\circ} \mathrm{N}, 130.1^{\circ} \mathrm{E}$ & $18.3^{\circ} \mathrm{N}$ \\
October & $13.3^{\circ} \mathrm{N}, 134.5^{\circ} \mathrm{E}$ & $16.0^{\circ} \mathrm{N}$ \\
November & $10.1^{\circ} \mathrm{N}, 138.3^{\circ} \mathrm{E}$ & $13.6^{\circ} \mathrm{N}$ \\
\hline
\end{tabular}

from July (26 out of $100 \mathrm{TCs} ; 26.0 \%$ ) to August (20 out of 115 TCs; $17.4 \%$ ) and September (24 out of 110 TCs; $21.8 \%)$. Afterward, the ratio reaches its maximum phase in October (29 out of $76 \mathrm{TCs} ; 38.1 \%)$ and November $(23$ out of 41 TCs, $56.1 \%$ ). Spatially, the mean genesis location for the migratory TCs and their mean latitudinal location to enter the SCS (i.e., the latitude when a TC crosses the $120^{\circ} \mathrm{E}$ longitude) in the July-November season are summarized in Table 1 . The averages of genesis locations can be separated into two groups. The migratory TCs in July, August, and September tend to form in a more western (west of $132^{\circ} \mathrm{E}$ ) and northern (north of $14.5^{\circ} \mathrm{N}$ ) location than TCs in October and November (east of $134.5^{\circ} \mathrm{E}$ and south of $13.3^{\circ} \mathrm{N}$ ). The northward-displaced formative locations result in a decreased ratio of the migratory TCs in August and September, while the southward-shifted formative locations lead to an increased ratio in the remaining months (Chen et al. 2017). The southeastward displacement of TC genesis locations in October and November is associated with a southward shift of the ET that extends eastward in the tropical region (e.g., Lander 1996; Wu et al. 2012). The mean of latitudinal locations for TCs entering the SCS can also be separated into two types. It is at a more northern (north of $18.1^{\circ} \mathrm{N}$ ) latitude in July-September than in October-November (south of $16.0^{\circ} \mathrm{N}$ ). Overall, the mean entry latitude is at a more northern location than the mean genesis latitude. This result indicates that the migratory TCs mainly take a northwestward track to enter the SCS.

\section{Modulations of 30-60-day ISO on migratory TCs}

TCs are major weather events and their innate characteristics naturally merge with climate variability phenomena (Hsu et al. 2008). For example, Bi et al. (2015) found that the presence of real-strength TCs may impact overall ISO strength in the WNP. The level of impact depends greatly on the variable being used with smallerscale variability such as a vorticity being substantially impacted by TC presence while large-scale variability 
such as a streamfunction is only nominally affected. Their results indicate that the impact of a TC on climate anomalies is more influential on features whose spatial scale is more akin to that of the TCs under consideration. For instance, in the case of the 10-24-day ISO, TCs may enhance the overall strength of such small spatial anomalies, which raises a question related to the mixture of TC signals into the 10-24-day ISO (Aiyyer et al. 2012). On the other hand, the 30-60-day ISO and TCs are very different in terms of spatial size (4000-5000 vs $500-800 \mathrm{~km})$ and frequency band (30-60 vs $2-14$ days). Under these circumstances, the 30-60-day ISO is thought to be much less influenced by TC presence (Wu and Takahashi 2018). Therefore, in this study, intraseasonal modulation of the movement of the migratory TCs focuses on the effect of the 30-60-day ISO during active TC seasons from July to November. Variability in climatological circulations such as the WPSH, MT, and ET is also examined. The day of TC genesis is defined as day 0 , while $N$ days after (before) TC genesis is referred to as day $N($ day $-N)$. The large-scale ISO circulation is represented by $850-\mathrm{hPa}$ streamfunction (S850), while convection activity is represented by outgoing longwave radiation (OLR). Both the 30-60-day S850 and OLR anomalies are extracted by a Lanczos filter scheme (e.g., Duchon 1979) with all daily data from 1979 to 2015.

The composite 30-60-day S850 anomalies and TC locations on day -4 , day 0 , day 4 , and day 8 of the migratory TCs in July are shown in Fig. 4. Superimposed on S850 anomalies are 30-60-day anomalies of steering flows (vectors) integrated from 850 to $300 \mathrm{hPa}$. Hereafter, composite $\mathrm{S} 850$ anomalies significant at the 0.1 level of the Student's $t$ test are shaded. As revealed by statistically significant patterns, the salient 30-60-day S850 feature on day -4 is an anomalous anticyclone to the southeast of Japan (Fig. 4a). On day 0, this anomalous anticyclone moves northwestward to a region northeast of the SCS with intensified magnitude (Fig. 4b). The migratory TCs tend to form to the south of this elongated anomalous anticyclone where anomalous easterly flows exist. On day 4 (Fig. 4c), this anomalous anticyclone shrinks northwestward. Meanwhile, TCs move along with anomalous easterly/southeasterly flows in the southern periphery of this anomalous anticyclone to enter the northern SCS. On day 8, the anomalous anticyclone remains in the same location, but with weakened magnitude (Fig. 4d).

The above anticyclonic anomaly spatially overlaps with the WPSH in July (Fig. 2a). The large-scale circulation variability in the low latitudes normally relates to convection variability. As such, the associated variability features of tropical convections are examined from the 30-60-day OLR anomalies, while variations of the WPSH are illustrated by 1510-gpm contours of total Z850. OLR anomalies significant at the 0.1 level of the Student's $t$ test are hereafter shaded. For convection variability, the 30-60-day OLR anomalies exhibit enhanced convections (negative values) in the SCS on day -4 (Fig. 4 e) that become significant and more intense on day 0 before the arrival of the migratory TCs (Fig. 4f). This enhancement continues on day 4 (Fig. 4g) through to day 8 (Fig. 4h). Meanwhile, suppressed convections (positive OLR anomalies) occur in a region to the northeast of the SCS, a region that spatially coincides with an anomalous anticyclone. The WPSH extends westward from day -4 to day 0 , remains at the same position from day 0 to day 4 , and retreats eastward on day 8. The WPSH is accompanied by suppressed 30 60-day convections. These results reveal that tropical convections are enhanced over the SCS prior to the arrival of the migratory TCs. This provides favorable conditions for TCs to move into and develop in the SCS. Other favorable conditions include the westwardintensified WPSH and anomalous easterly flows to the south of a 30-60-day anomalous anticyclone to the northeast of the SCS.

In August, composite 30-60-day S850 anomalies associated with the migratory TCs feature a significant anomalous anticyclone to the east of the northern SCS on day -4 (Fig. 5a). This anomalous anticyclone intensifies and moves northwestward to the northeast of the SCS on day 0 (Fig. 5b), while the migratory TCs tend to form in its southern section. This anomalous anticyclone further intensifies on day 4 (Fig. 5c) and steers the migratory TCs into the northern SCS via anomalous easterly/southeasterly flows at its southern periphery. The anomalous anticyclone stays at the same location on day 8 (Fig. 5d). The 30-60-day OLR anomalies exhibit enhanced convection over the northwestern SCS on day -4 (Fig. 5e) that continuously expands eastward and southward on day 0 (Fig. 5f), day 4 (Fig. 5 g), and day 8 (Fig. 5h). The above OLR anomalies in the SCS are statistically significant, although not strong. Noticeable suppressed convections exist in the region northeast of the SCS on day 0 , day 4 , and day 8 that spatially coincide with the strengthening 30-60-day anomalous anticyclone. During these days, the WPSH (represented by 1510-gpm Z850 contours) extends westward evidently from day -4 to day 0 and displaces northward on day 4 and southward on day 8 . The above results disclose that the steering processes for the migratory TCs in August are similar to those in July. A westward intensification of the WPSH coincides with the appearance of a 30-60-day anomalous anticyclone to the northeast of the SCS. These two features steer TCs in their southern 

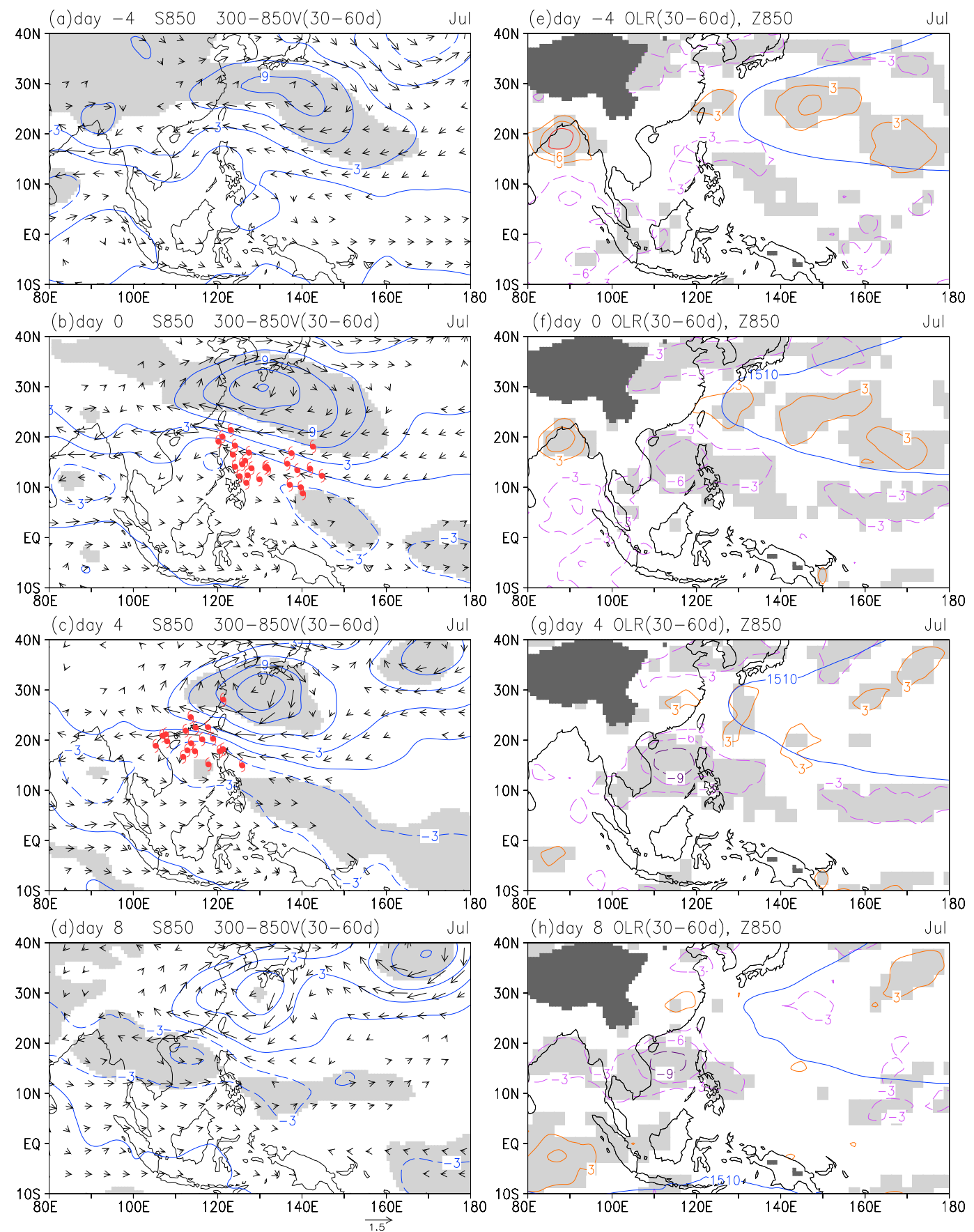

FIG. 4. Composite 30-60-day (left) S850 and (right) OLR anomalies on (a),(e) day -4, (b),(f) day 0, (c),(g) day 4, and (d),(h) day 8 of the migratory TCs in July. Composite S850 anomalies are superimposed with TCs on day 0 and day 4. S850 and OLR anomalies significant at the 0.1 level of the Student's $t$ test are shaded. S850 anomalies are superimposed by 30-60-day steering flows integrated from 850 to $300 \mathrm{hPa}$. OLR anomalies are superimposed by 1510 -gpm contours of total 850 -hPa height. Contour intervals are $3 \times 10^{5} \mathrm{~m}^{2} \mathrm{~s}^{-1}$ for $\mathrm{S} 850$ anomalies and $3 \mathrm{~W} \mathrm{~m} \mathrm{~m}^{-2}$ for OLR anomalies.

peripheries via anomalous easterly/southeasterly flows into the SCS. Meanwhile, enhanced 30-60-day convections in the SCS prior to TC arrival provide another favorable condition for TCs to move in and develop.
In September, the significant 30-60-day S850 anomalies on day -4 are a meridional circulation pair with an anomalous anticyclone north of $20^{\circ} \mathrm{N}$ and a zonally elongated anomalous cyclone to the south with a center 

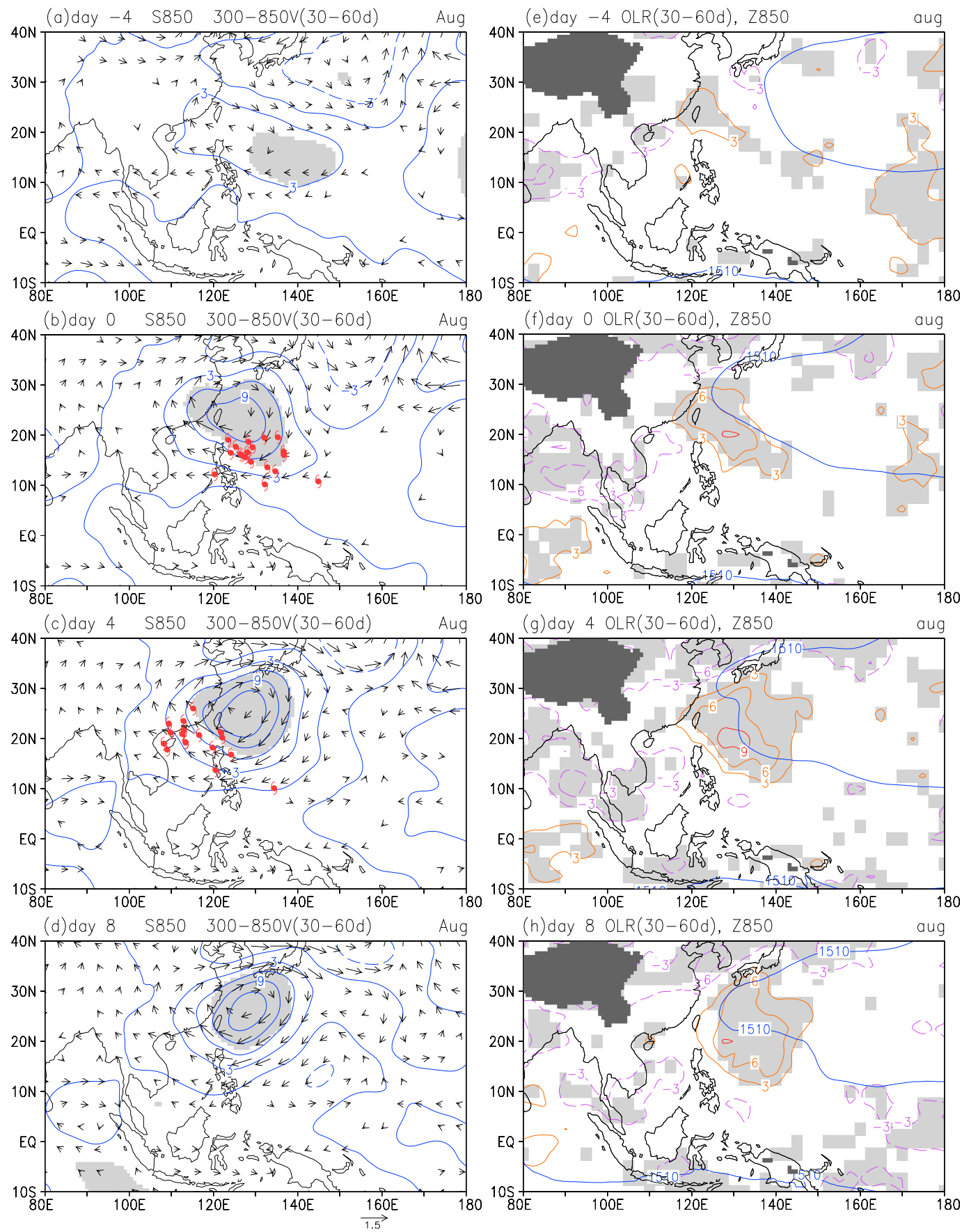

FIG. 5. As in Fig. 4, but for composite 30-60-day (left) S850 and (right) OLR anomalies on (a),(e) day -4, (b),(f) day 0, (c),(g) day 4, and (d),(h) day 8 of the migratory TCs in August. TCs and 1510-gpm Z850 contours are superimposed on S850 and OLR anomalies, respectively.

around $5^{\circ} \mathrm{N}$ (Fig. 6a). On day 0 , the anomalous cyclone intensifies zonally, while the anomalous anticyclone weakens (Fig. 6b). TC genesis scatters in between these two circulation anomalies where anomalous easterly flows exist. On day 4, the anomalous cyclone further intensifies with a major center over the SCS, while the anomalous anticyclone to the northeast of the SCS continuously weakens (Fig. 6c). The migratory TCs are steered by anomalous easterly/southeasterly flows sandwiched by this circulation pair to move westward/ northwestward toward the northern SCS. This circulation pair stays at the same location, but with weaker 

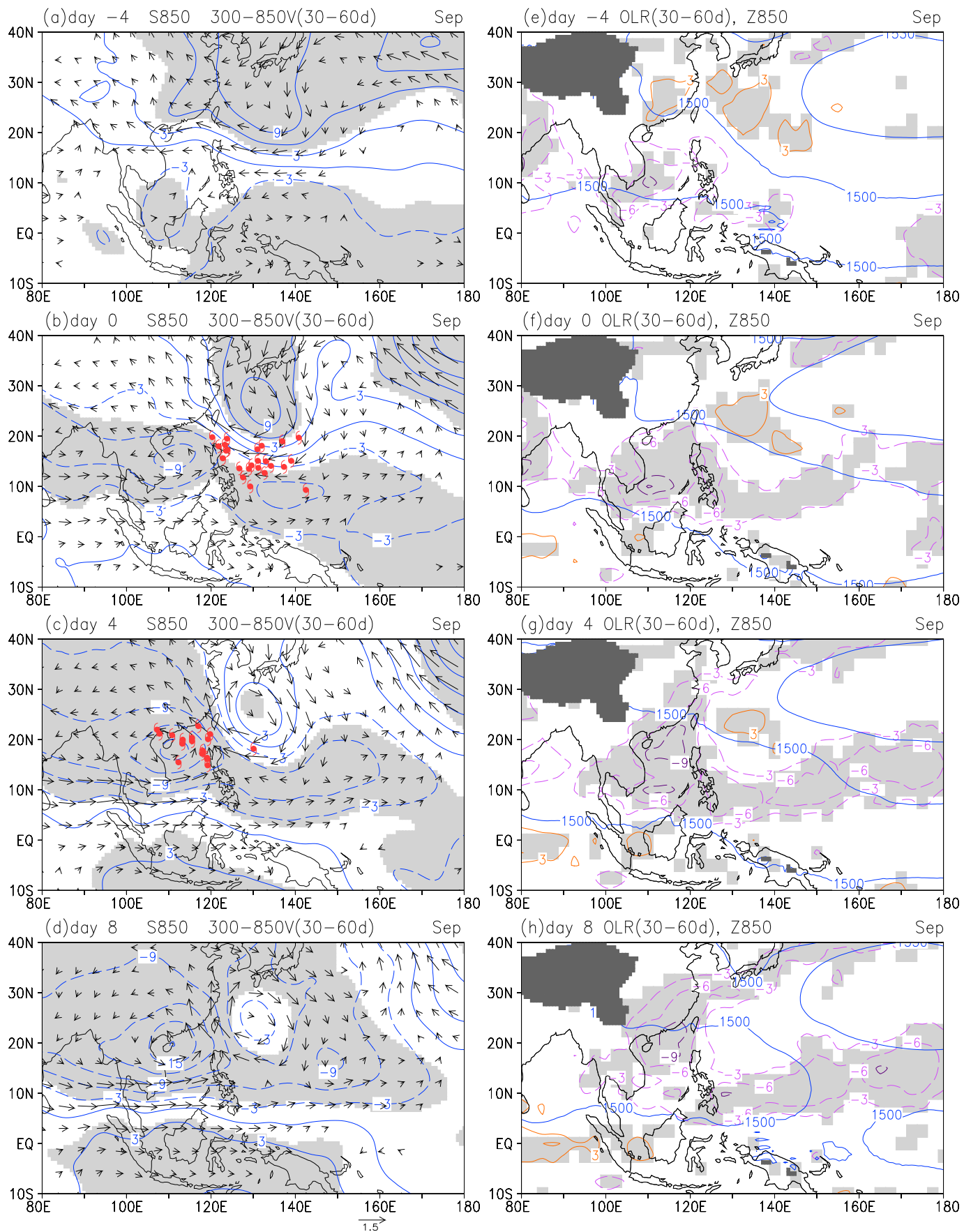

FIG. 6. As in Fig. 4, but for composite 30-60-day (left) S850 and (right) OLR anomalies on (a),(e) day -4, (b),(f) day $0,(\mathrm{c}),(\mathrm{g})$ day 4 , and (d),(h) day 8 of the migratory TCs in September. TCs and 1500-gpm Z850 contours are superimposed on S850 and OLR anomalies, respectively.

intensity on day 8 (Fig. 6d). In accordance with the evolution of the circulation pair, the 30-60-day OLR anomalies reveal that enhanced convection appears in the southern SCS on day -4 (Fig. 6e) that extends eastward into the tropical WNP on day 0 (Fig. 6f). The convections continuously enhance eastward and northward on day 4 (Fig. 6g) and day 8 (Fig. 6h). As revealed by 1500 -gpm Z850 contours in Fig. 6e, the existence of an elongated 30-60-day anomalous cyclone is related to an intensified MT extending southeastward from the Bay of Bengal into the tropical central Pacific. The extended MT strengthens with an increased 

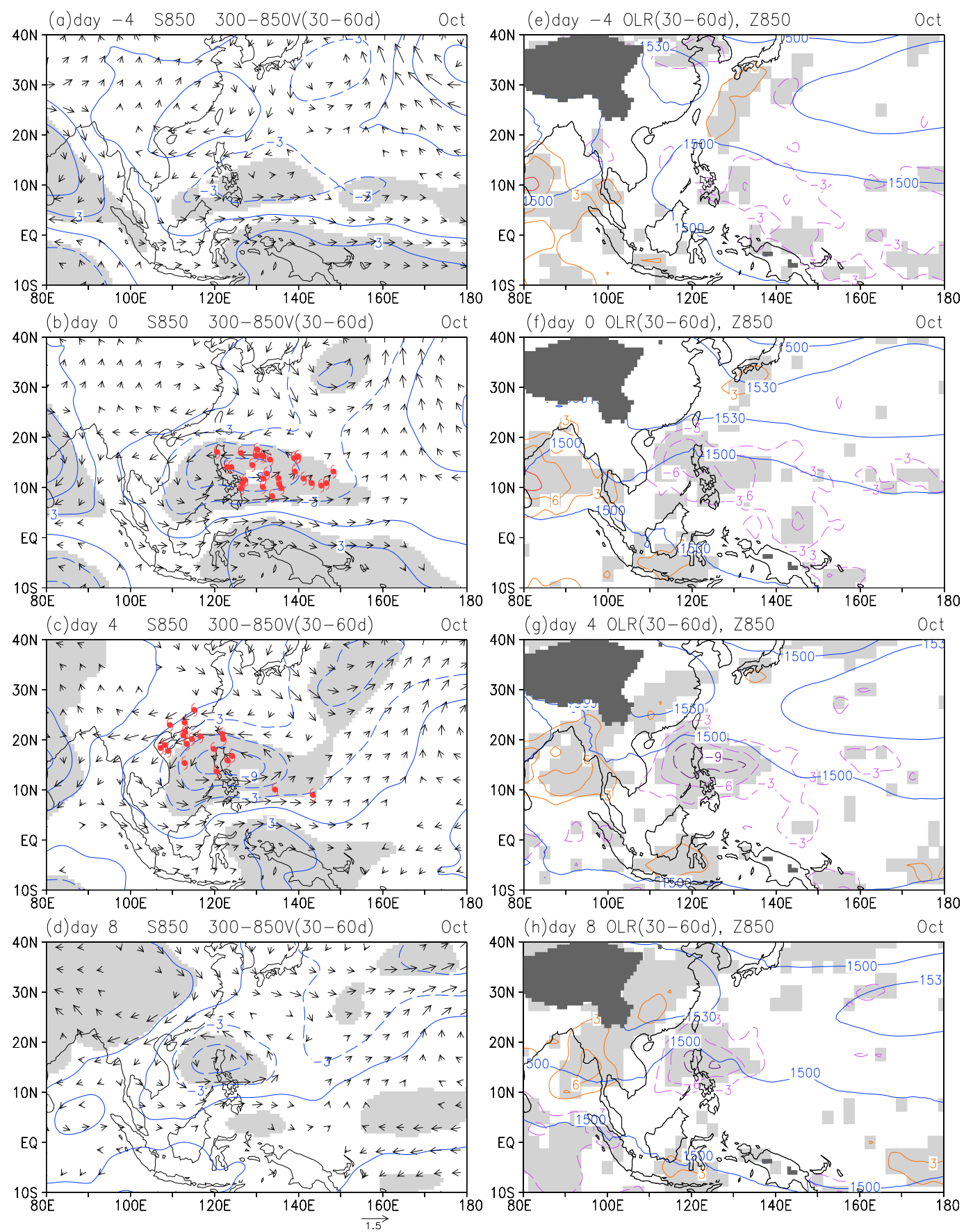

FIG. 7. As in Fig. 4, but for composite 30-60-day (left) S850 and (right) OLR anomalies on (a),(e) day -4, (b),(f) day $0,(\mathrm{c}),(\mathrm{g})$ day 4 , and (d),(h) day 8 of the migratory TCs in October. TCs and 1500- and 1530-gpm Z850 contours are superimposed on S850 and OLR anomalies, respectively.

meridional domain on day 0 and day 4 in company with the intensifications of tropical convections and the anomalous cyclone across the SCS and the WNP. These results indicate that TCs are steered by anomalous easterly/southeasterly flows imposed by the 30-60-day circulation pair and the MT to move toward the SCS where enhanced convections provide favorable conditions for TCs to grow.

In October, the 30-60-day S850 anomalies associated with the migratory TCs exhibit a significant cyclonic anomaly with a center to the east of the Philippines on day -4 (Fig. 7a). This cyclonic anomaly intensifies 
zonally to cross the SCS and the tropical WNP on day 0 (Fig. 7b). The migratory TCs tend to form in the WNP within this cyclonic anomaly. On day 4, the cyclonic anomaly has its center extending westward into the SCS, while TCs are steered by anomalous easterly flows in the northern section of this cyclonic anomaly to move westward/northwestward along this cyclonic anomaly to enter the northern SCS (Fig. 7c). This cyclonic anomaly weakens at the same location on day 8 (Fig. 7d). The 3060-day OLR anomalies on day -4 feature enhanced convections in the tropical WNP to facilitate TC formation. These enhanced convections are within the ET as indicated by 1500 -gpm Z850 contours (Fig. 7e). On day 0 , enhanced tropical convections stretch northwestward from the tropical WNP into the SCS, accompanied by a westward extension of the ET across the SCS into the Bay of Bengal (Fig. 7f). The enhanced convections continuously strengthen in the SCS on day 4 (Fig. 7g) and day 8 (Fig. 7h), while the ET expands both zonally and meridionally in these days. The above results reveal that enhanced convective anomalies over the SCS and WNP are accompanied by an elongated cyclonic anomaly and an intensified ET stretching from the WNP into the SCS. The cyclonic anomaly and intensified ET induce anomalous easterly flows in their northern section that provide favorable conditions for the migratory TCs to move within them toward the SCS. From day -4 to day 8 , the 30-60-day anomalous cyclone shows a northwestward propagation from the tropical WNP into the SCS. This is consistent with the findings of Hsu and Weng (2001) and Tsou et al. (2005) in that there is a northwestward propagation of the 30-60-day ISOs from the Philippines to a region near $20^{\circ} \mathrm{N}$.

In November, the prominent feature of the 30-60-day ISO appears as an eastward-propagating cyclonic anomaly. Its center is located to the north of the Bay of Bengal on day -4 (Fig. 8a), extends from the Bay of Bengal into the SCS on day 0 (Fig. 8b), situates over the SCS on day 4 (Fig. 8c), and displaces eastward to the south of Taiwan on day 8 (Fig. 8d). TC genesis scatters over the southeastern sector of this cyclonic anomaly along the extended tip region on day 0 where anomalous easterly flows extend from the tropical WNP into the northern SCS. On day 4, TCs mainly move along anomalous easterly flows toward the northern section of the center of the cyclonic anomaly in the northern SCS. The 30-60-day OLR anomalies reveal that enhanced convections stretch northwestward from the tropical WNP into the SCS prior to TC genesis on day -4 (Fig. 8e). These enhanced convections are embedded in the ET represented by 1500 -gpm Z850 contours. Enhanced convections over the SCS persist on day 0 (Fig. 8f) and day 4 (Fig. 8g) and are accompanied by an intensified ET extending westward from the WNP into the SCS on day 0 and farther into the Indochina Peninsula on day 4. Both the convections and ET weaken on day 8 (Fig. 8h). Persistently enhanced convections over the SCS and WNP are associated with an eastward propagation of the 30-60-day anomalous cyclone with its center moving from the Bay of Bengal on day -4 to the SCS on day 4. The arrival of this cyclonic anomaly center is accompanied by an intensification of the ET with its boundary expanding northwestward from the southeastern SCS on day 0 into the northern SCS on day 4. The intensified ET coincides with enhanced anomalous easterly flows in its northern periphery that facilitate the westward movement of the migratory TCs from the WNP into the SCS along the ET and a 30-60-day cyclonic anomaly.

The above analyses reveal different modulating effects of the 30-60-day circulations on movements of the migratory TCs. The dominant effects are attributable to an anomalous anticyclone to the north of $20^{\circ} \mathrm{N}$ in July and August, a circulation pair on two sides of $20^{\circ} \mathrm{N}$ in September, and an anomalous cyclone to the south of $20^{\circ} \mathrm{N}$ in October and November. TC movements into the SCS are steered by anomalous easterly/southeasterly flows in July, August, and September, but facilitated by an anomalous cyclone in October and November. The above anomalous easterly/southeasterly flows and anomalous cyclone are accompanied by enhanced 30 60-day tropical convective anomalies over the SCS prior to the arrival of the migratory TCs.

\section{TC-ISO phase relationships for migratory TCs}

TC tracks have been found to relate to certain ISO phases (e.g., Li and Zhou 2013). It is of interest to examine the major ISO phase modulating the westward/ northwestward tracks of the migratory TCs. The 30-60day bandpass filtered OLR anomalies from July to November are subject to the empirical orthogonal analysis (EOF). The first two EOF modes are used in phase categorizations following the definitions of Wheeler and Hendon (2004). OLR anomalies used in the EOF analysis are in a tropical domain of $40^{\circ} \mathrm{E}-180^{\circ}, 15^{\circ} \mathrm{S}-25^{\circ} \mathrm{N}$ for the 30-60-day ISO.

Shown in Table 2 are numbers of the migratory TCs occurring in various 30-60-day ISO phases on the day TCs entering the SCS. For all 122 migratory TC cases with formative locations in the $120^{\circ}-150^{\circ} \mathrm{E}$ region, TC numbers are the largest in phases $6-7$ with 41 cases (33.6\%), followed by 34 cases $(27.8 \%)$ in phases $4-5$. TC numbers are comparable between phases 4-5 and 6-7 in July, August, and September, but dominated by phases 6-7 in October and November. The composite patterns 

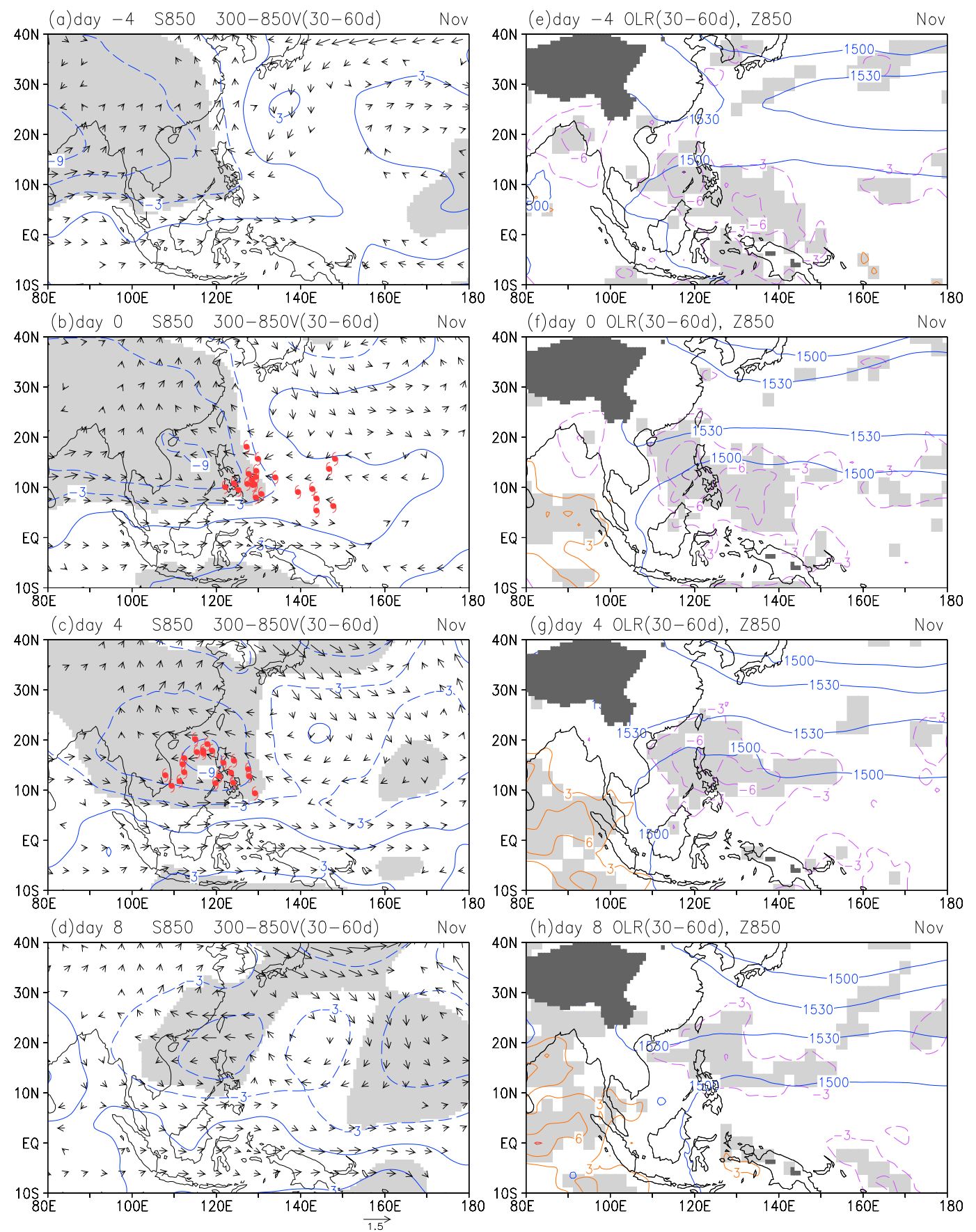

FIG. 8. As in Fig. 4, but for composite 30-60-day (left) S850 and (right) OLR anomalies on (a),(e) day -4, (b),(f) day $0,(\mathrm{c}),(\mathrm{g})$ day 4 , and (d),(h) day 8 of the migratory TCs in November. TCs and 1500- and 1530-gpm Z850 contours are superimposed on S850 and OLR anomalies, respectively.

of 30-60-day OLR anomalies constructed from the EOF analysis for phases 4-7 are illustrated in Fig. 9. OLR anomalies are superimposed by $30-60$-day $850-\mathrm{hPa}$ winds for the same days to illustrate circulation flows. The common features of these composite patterns are negative OLR anomalies (enhanced convections) over the SCS that migrate northward. The anomalous OLR center inside the SCS is to the south of $10^{\circ} \mathrm{N}$ in phase 4 (Fig. 9a) and around $10^{\circ} \mathrm{N}$ in phase 5 (Fig. 9b). These enhanced convections are associated with convergent flows appearing as anomalous easterly flows from the WNP into the northern SCS, facilitating the migration of 
TABLE 2 . The number of the migratory TC cases in various 30 60-day ISO phases. The TC-ISO phase relationship is determined by the day when TCs first enter the SCS. The two largest numbers in each month and total are in bold.

\begin{tabular}{lrrrr}
\hline \hline & \multicolumn{4}{c}{$30-60$-day ISO phase } \\
\cline { 2 - 5 } \multicolumn{1}{c}{ Month } & $2-3$ & $4-5$ & $6-7$ & $8-1$ \\
\hline July & 5 & $\mathbf{8}$ & $\mathbf{7}$ & 6 \\
August & 3 & $\mathbf{6}$ & $\mathbf{6}$ & 5 \\
September & 4 & $\mathbf{8}$ & $\mathbf{7}$ & 5 \\
October & $\mathbf{7}$ & 6 & $\mathbf{1 0}$ & 6 \\
November & 2 & $\mathbf{6}$ & $\mathbf{1 1}$ & 4 \\
Total & 21 & $\mathbf{3 4}$ & $\mathbf{4 1}$ & 26 \\
\hline
\end{tabular}

TCs into the SCS. In phases 6 and 7, the anomalous negative OLR center moves to the north of $10^{\circ} \mathrm{N}$ over the northern SCS. The convective anomaly extends eastward into the WNP that provides favorable conditions for TCs to move inside it from the WNP toward the SCS. The above analyses reveal two 30-60-day processes facilitating TC migration into the SCS. The most common one throughout July-November, as revealed by phases $6-7$, is the occurrence of enhanced convective anomalies extending from the SCS into the WNP. They allow TCs to move inside them to enter the SCS. The second one, as revealed by phases $4-5$, is the appearance of anomalous easterly flows from the WNP into the SCS. These flows are associated with an anomalous anticyclone to the northeast of the SCS in July-August (Figs. 4 and 5) or a circulation pair with an anomalous anticyclone to the north and an anomalous cyclone to the south during September (Fig. 6).

\section{Variability of climatological circulations associated with migratory $\mathrm{TCs}$}

Variability features of the climatological circulations associated with TC genesis are specifically examined in this section. The circulation features of the WPSH, MT, and ET on day 0 of the migratory TCs are illustrated by Z850. Shown in Fig. 10 are total Z850 contours for the climatological mean (blue contours) and the composite mean of daily data on day 0 of the migratory TCs (red contours) for each month from July to November. As revealed by the 1480-, 1490-, and 1500-gpm contours in July (Fig. 10a) and August (Fig. 10b), genesis of the migratory TCs is associated with a westward intensification of the WPSH. The migratory TCs tend to form in a region south of the intensified WPSH where the MT also intensifies. TCs are steered by anomalous easterly/ southeasterly flows toward the SCS. Figure 10c shows that genesis of the migratory TCs in September is related to a southeastward intensification of the MT, as
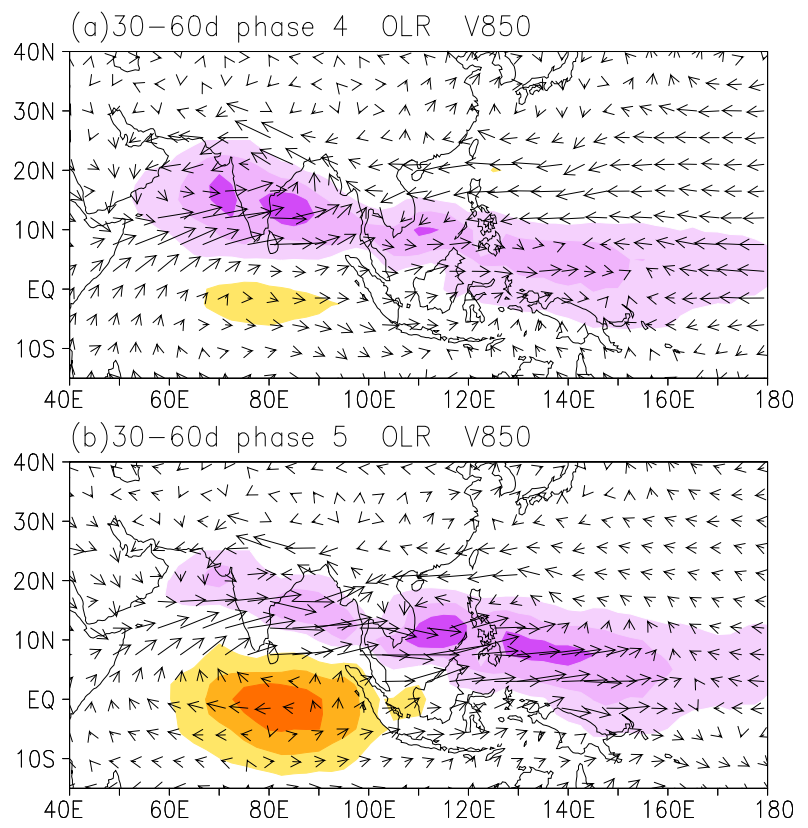

(c) $30-60 d$ phase 6 OLR V850
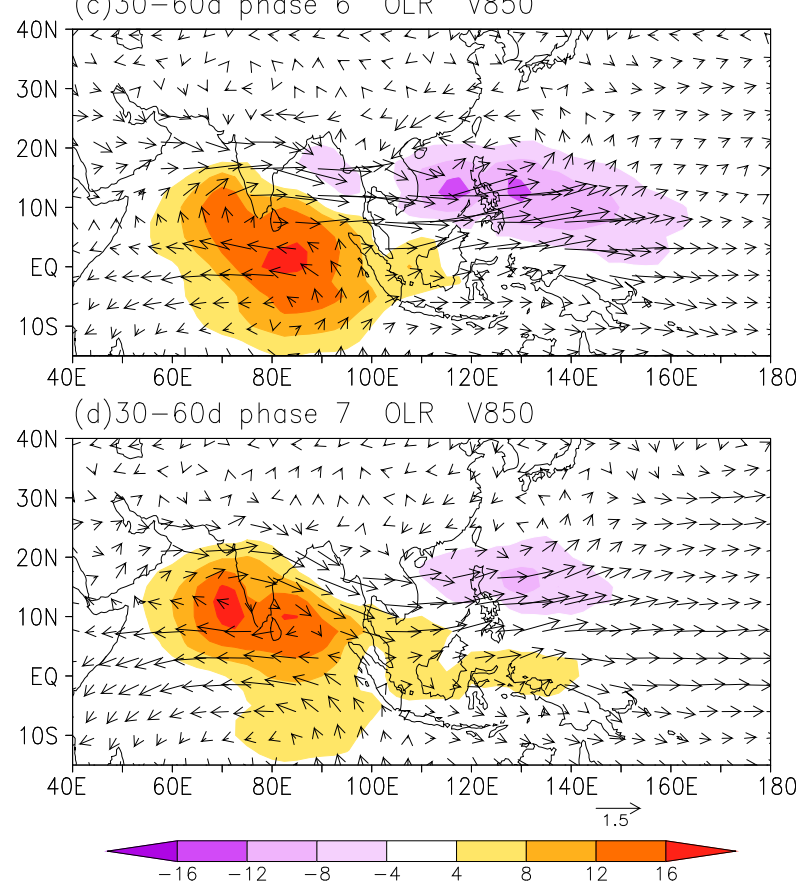

FIG. 9. Composite OLR and $850-\mathrm{hPa}$ wind anomalies for (a) phase 4, (b) phase 5, (c) phase 6, and (d) phase 7 of the 30-60day ISO.

revealed by the 1490 - and 1500 -gpm contours. The migratory TCs mostly form in the Philippine Sea right over the northern/northeastern section of the intensified MT where TCs are assisted by anomalous southeasterly flows to move toward the SCS. The 1500-gpm Z850 contours in October (Fig. 10d) depict the ET mainly intensifying westward with a minor northward 

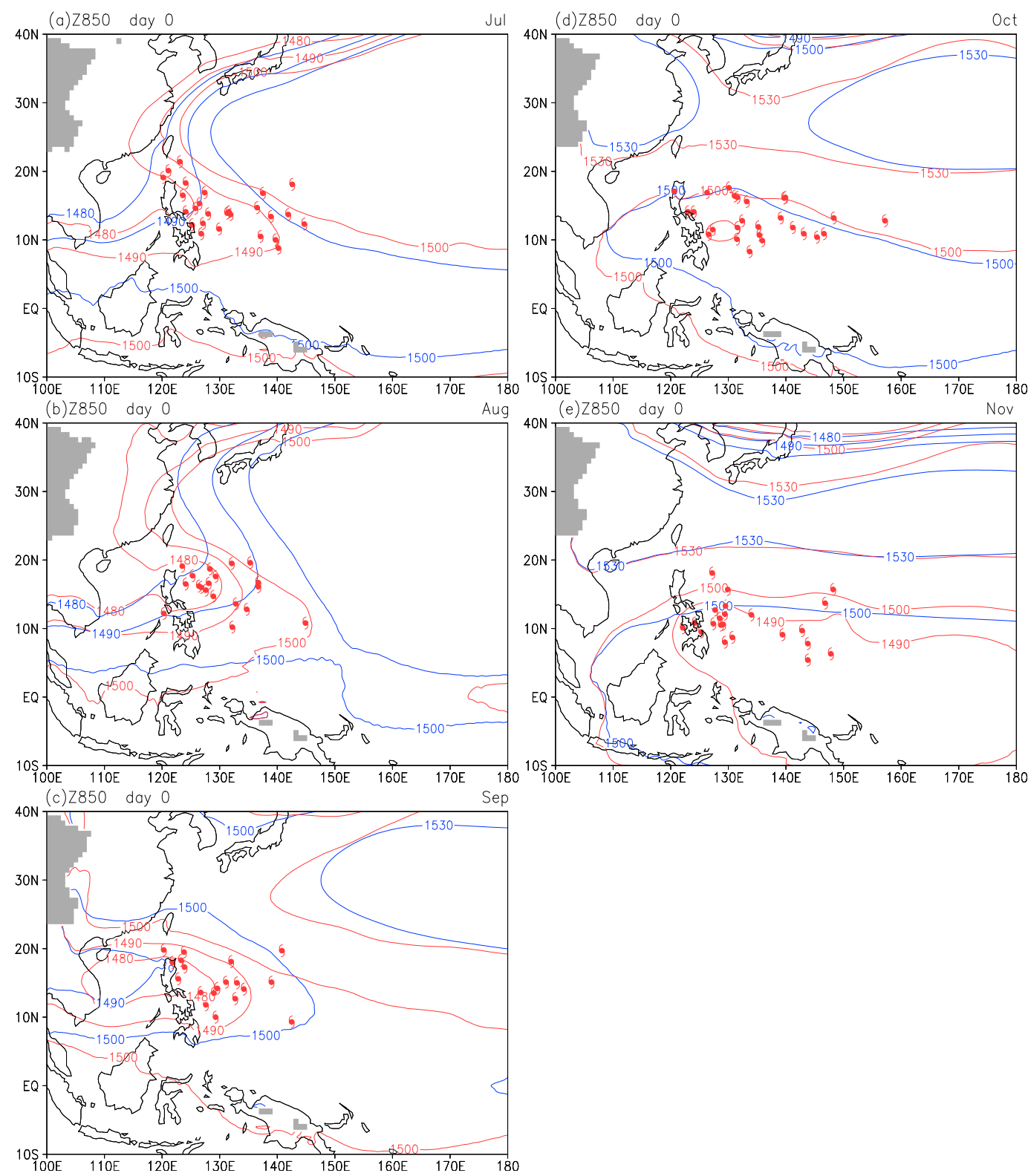

FIG. 10. Composite Z850 contours to depict spatial features of the WPSH, MT, and ET on day 0 of the migratory TCs (red contours) and the climatological mean (blue contours) in (a) July, (b) August, (c) September, (d) October, and (e) November. TC genesis locations in each month are marked by red symbols.

intensification. To the north of $20^{\circ} \mathrm{N}$, the subtropical high (represented by the 1530-gpm contour) strengthens to possess a closed contour across East Asia and the subtropical WNP. TCs form in a region adjacent to the northern boundary of the ET and are driven by easterly/ southeasterly flows to move within this trough toward the SCS. The spatial patterns in November (Fig. 10e) are similar to those in October, featuring an intensified ET depicted by 1490- and 1500-gpm contours and a zonally extending subtropical high depicted by 1530 -gpm contours. TC formation scatters zonally across the WNP along the northern boundary of the ET around $10^{\circ} \mathrm{N}$. These TCs are facilitated by easterly/southeasterly flows to move within the ET toward the SCS.

\section{Modulations of 30-60-day ISO on recurving TCs}

The above analyses have demonstrated that the 30 60-day ISO can effectively modulate the migratory TCs via different large-scale processes from July to 
November. For TCs with a different track, can the 30 60-day ISO also exert effective modulations on their movements? If yes, are their modulating processes different from those modulating the migratory TCs? These questions need to be examined to clarify which specific modulations the 30-60-day ISO has on TC movement. To this end, a relatively different TC track is selected for comparison. TCs originally forming in the $120^{\circ}-150^{\circ} \mathrm{E}$, $0^{\circ}-25^{\circ} \mathrm{N}$ region and later recurving northward to a region east of $122^{\circ} \mathrm{E}$ and north of $25^{\circ} \mathrm{N}$ are referred to as the recurving TCs in this study. The relative percentage of the recurving TCs to total TCs forming in the $120^{\circ}-$ $150^{\circ} \mathrm{E}, 0^{\circ}-40^{\circ} \mathrm{N}$ region is $16.0 \%$ ( 16 out of $100 \mathrm{TCs}$ ) in July, $15.7 \%$ (18 out of 115 TCs) in August, $16.4 \%$ (18 out of $100 \mathrm{TCs}$ ) in September, $19.7 \%$ (15 out of 76 TCs) in October, and $12.2 \%$ ( 5 out of 41 TCs) in November. We thus examine the modulating processes of the 30-60-day ISO on the recurving TCs for July-October. November is excluded from the analysis due to its small number of cases (only 5).

Composite 30-60-day anomalies of S850 and steering flows integrated from 850 to $300 \mathrm{hPa}$ from day -4 to day 8 for the recurving TCs in July and August are shown in Fig. 11. In July, the significant feature on day -4 (Fig. 11a) is an anomalous cyclone with its center extending northeastward from the northern SCS toward Japan. On day 0 (Fig. 11b), TCs tend to form in a region to the east and southeast of the anomalous cyclonic center where anomalous southerly/southeasterly flows exist. There is an anomalous anticyclone to the northeast of the anomalous cyclone to enhance anomalous southeasterly flows between them. On day 4 (Fig. 11c), TCs are steered by anomalous southeasterly flows to recurve northward/ northwestward toward the East China Sea and Japan along the eastern section of the anomalous cyclone. On day 8 (Fig. 11d), the pair of cyclonic and anticyclonic anomalies weakens. In August, the dominant feature on day -4 (Fig. 11e) is an anomalous cyclone extending from Asian landmasses into Japan with its center to the east of Taiwan. This cyclonic anomaly is paired with an anticyclonic anomaly on its northeastern side. On day 0 (Fig. 11f), TCs tend to form in a region south of this circulation pair. On day 4 (Fig. 11g), TCs are driven by anomalous southeasterly flows between this cyclonicanticyclonic circulation pair to recurve northward. On day 8 (Fig. 11h), the anomalous circulation pair weakens in intensify.

The composite S850 and steering flow anomalies for September and October are shown in Fig. 12. In September, the major circulation feature is a significant anomalous anticyclone to the northeast of Taiwan (Fig. 12a). On day 0 (Fig. 12b), the circulation feature changes to an anomalous cyclone overlying Taiwan and an anomalous anticyclone to the east of Japan with its center near the date line. TCs tend to form between these two circulation anomalies. On day 4 (Fig. 12c), the above circulation pair intensifies and becomes significant. TCs mainly follow anomalous southwesterly/ southerly flows along the eastern section of the anomalous cyclone to move northward. On day 8 (Fig. 12d), the cyclonic-anticyclonic circulation pair remains at the same position with similar intensity. In October, the 3060-day anomalies on day -4 (Fig. 12e) exhibit a significant anomalous cyclone with its center across the SCS and the tropical WNP. On day 0 (Fig. 12f), this anomalous cyclone intensifies with a southeasterlynorthwesterly extension, while an anomalous anticyclone appears on its northeastern side. TCs tend to form in the southeastern section of the anomalous cyclone where anomalous southeasterly flows exist. On day 4 (Fig. 12g), both the anomalous cyclone and anticyclone strengthen to enhance the anomalous southeasterly flows between them. These anomalous flows steer TCs to move northward/northwestward along the eastern section of the anomalous cyclone. On day 8 (Fig. 12h), the cyclonic-anticyclonic circulation pair remains at a similar intensity at their locations.

The major circulation anomaly steering northward/ northwestward movements of the recurving TCs appears as a circulation pair with an anomalous cyclone to the west and an anomalous anticyclone to the east. TCs tend to form to the south of this circulation pair and follow anomalous southerly/southeasterly flows between this circulation pair or in the eastern section of the anomalous cyclone to move northward. The migratory TCs are steered by anomalous easterly flows to the south of an anomalous anticyclone in July and August, between a meridional circulation pair in September, and in the northern section of an anomalous cyclone in October and November. The above features demonstrate clearly that the modulating processes of the 30-60-day ISO on the recurving and migratory TCs are completely different and independent from each other.

\section{Variability of climatological circulations associated with recurving TCs}

With a similar approach used in Fig. 10, variability features of the climatological circulations associated with genesis (day 0 ) of the recurving TCs are depicted by composite Z850 contours in Fig. 13. In July (Fig. 13a) and August (Fig. 13b), composite Z850 contours on day 0 of the recurving TCs (red contours) exhibit an eastward intensification of the MT and an eastward retreat of the WPSH when compared with climatological patterns (blue contours). The intensified MT is related to a 

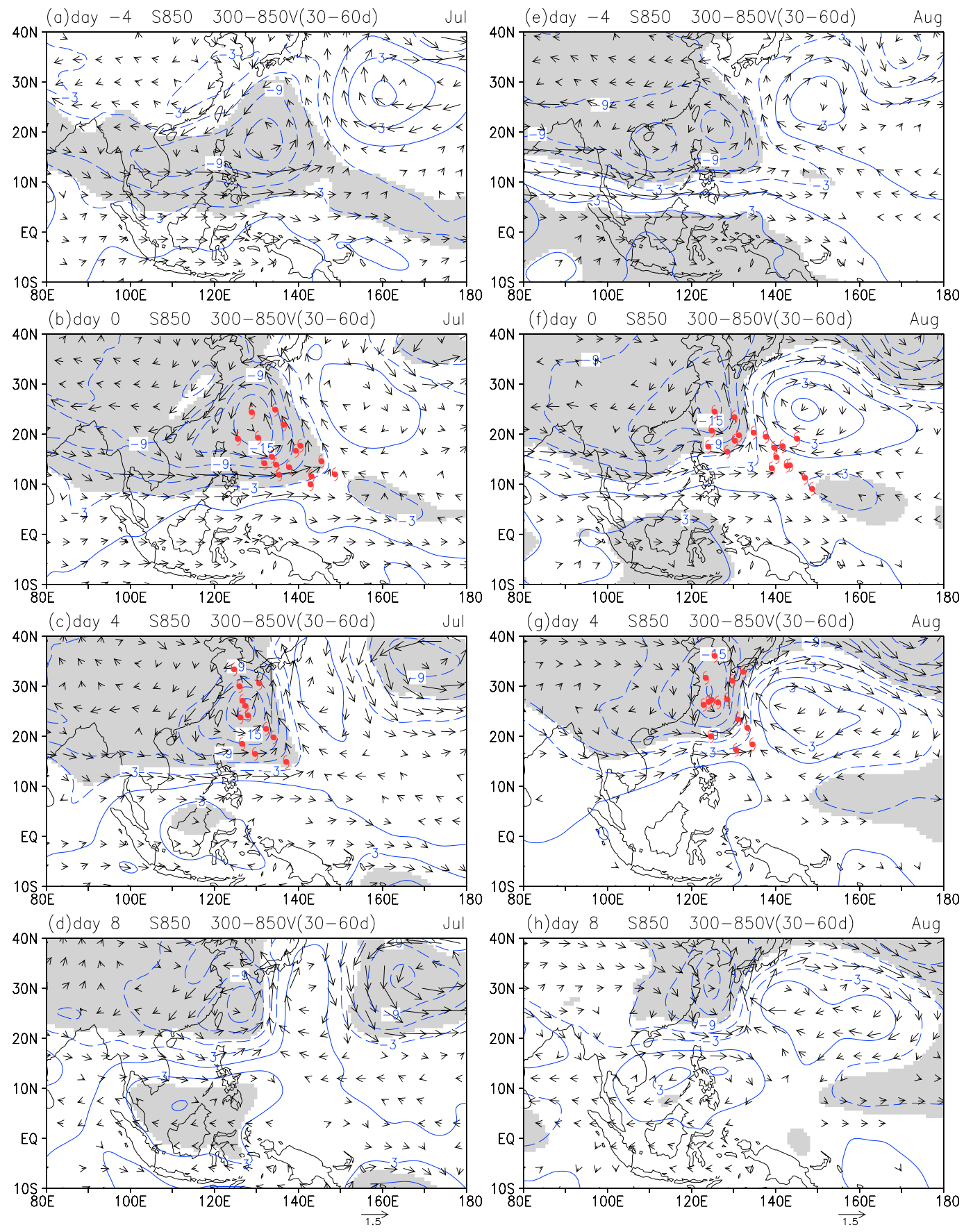

FIG. 11. Composite 30-60-day S850 and steering flow (integrated from 850 to $300 \mathrm{hPa}$ ) anomalies on (a),(e) day -4 , (b),(f) day 0, (c),(g) day 4, and (d),(h) day 8 of the recurving TCs in (left) July and (right) August. Composite S850 anomalies are superimposed with TCs on day 0 and day 4. S850 anomalies significant at the 0.1 level of the Student's $t$ test are shaded. Contour intervals are $3 \times 10^{5} \mathrm{~m}^{2} \mathrm{~s}^{-1}$ for $\mathrm{S} 850$ anomalies.

30-60-day anomalous cyclone with its center to the southeast of Taiwan (Fig. 11). In September (Fig. 13c), the salient features include an intensification of the MT in its climatological location in the Philippine Sea as revealed by the 1490 -gpm contours and a westward intensification of the WPSH. This variability feature is related to a 30-60-day anomalous cyclone with its center overlying the SCS. In October (Fig. 13d), the major variability features appear as the intensification and northward extension of the ET and a northward shift of 

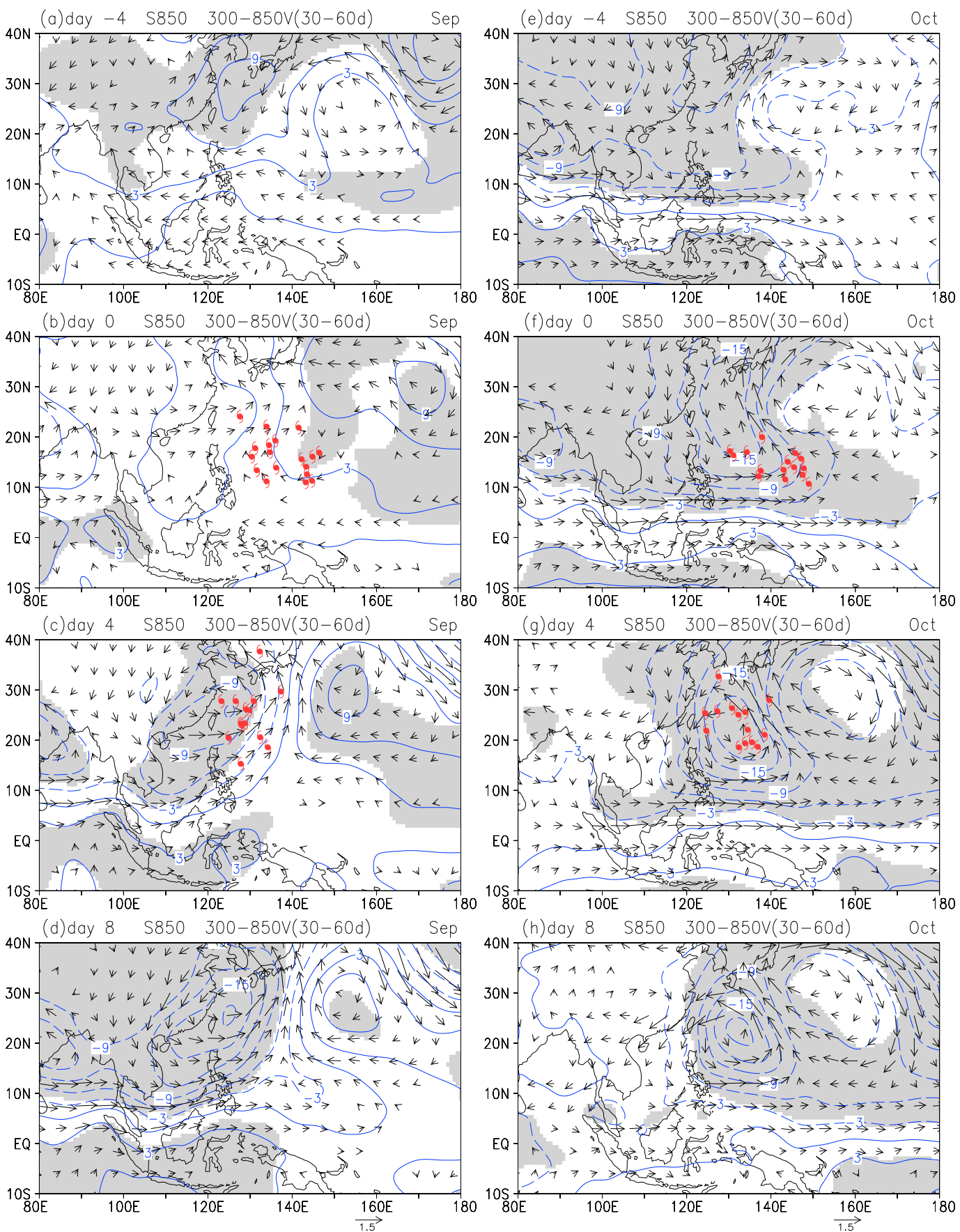

FIG. 12. As in Fig. 11, but for composite 30-60-day S850 and steering flow (integrated from 850 to $300 \mathrm{hPa}$ ) anomalies on (a),(e) day -4 , (b),(f) day 0 , (c),(g) day 4, and (d),(h) day 8 of the recurving TCs in (left) September and (right) October.

the WPSH. This variability is related to the appearance of a 30-60-day anomalous cyclone with a center to the east of the Philippines. There are some differences in variability features of the climatological circulations between the migratory and recurving TCs. In July and August, the migratory TCs are associated with a westward-intensified WPSH (Figs. 10a,b), while the recurving TCs are related to an eastward-retreated WPSH (Figs. 13a,b). In September, both the migratory and recurving TCs are associated with an intensified MT. The center of the intensification is located in the SCS for the migratory TCs (Fig. 10c), but in the 

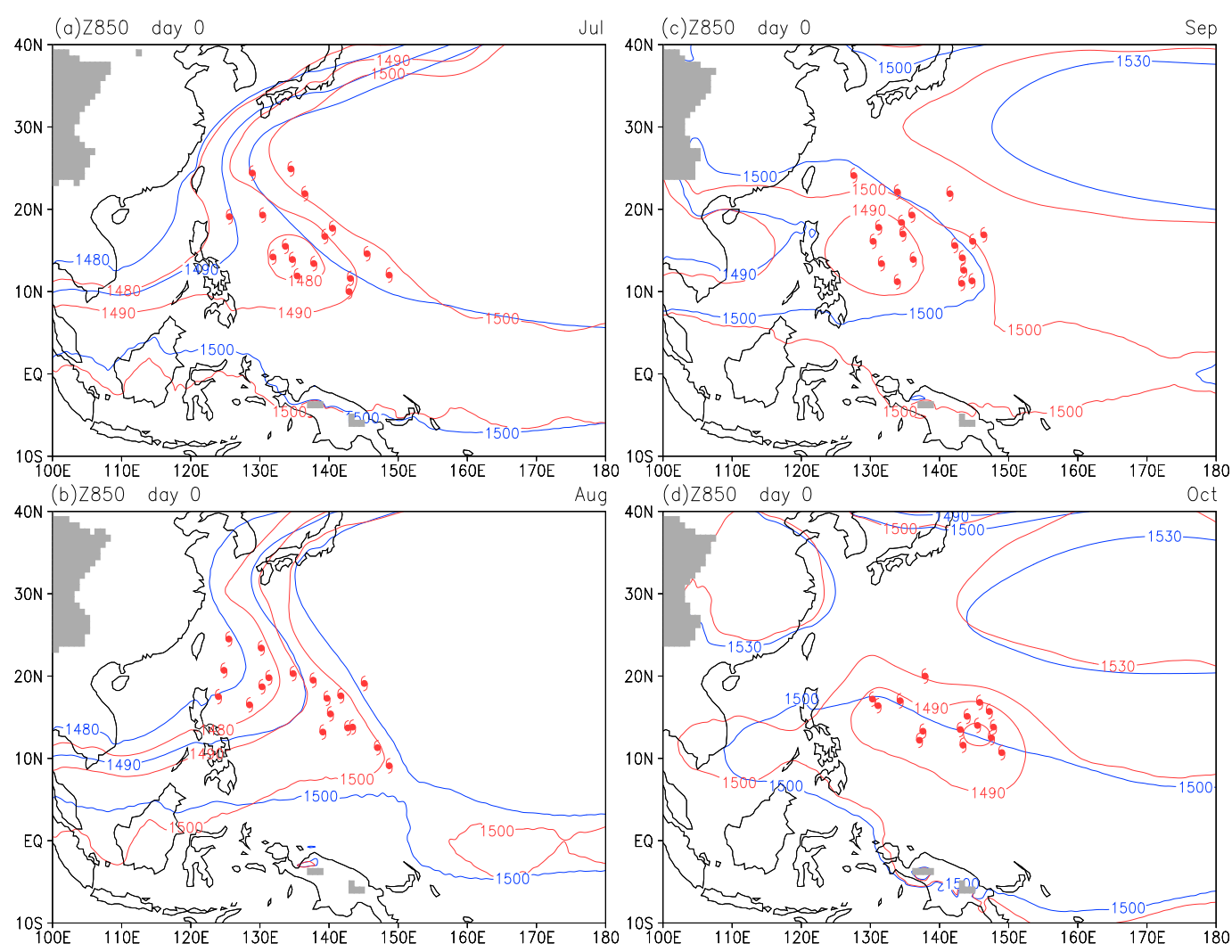

FIG. 13. Composite Z850 contours to depict spatial features of the WPSH, MT, and ET on day 0 of the recurving TCs (red contours) and for the climatological mean (blue contours) in (a) July, (b) August, (c) September, and (d) October. TC genesis locations in each month are marked by red symbols.

Philippine Sea for the recurving TCs (Fig. 13c). In October, both the ET and WPSH intensify westward for the migratory TCs (Fig. 10d) but strengthen northward for the recurving TCs (Fig. 13d). These results reveal that the variability of the climatological circulations impose different modulating effects on the migratory and recurving TCs to result in them having different tracks.

\section{Concluding remarks}

TCs forming in the WNP and later moving into the SCS are referred to as the migratory TCs in this study. Movements of the migratory TCs are mainly along the $10^{\circ}-20^{\circ} \mathrm{N}$ tropical region under the influence of ISO activity and climatological circulations including the WPSH, MT, and ET. How the 30-60-day ISO and the climatological circulations affect movements of the migratory TCs through the active TC season (JulyNovember) is examined. ISO modulating processes on TCs of different tracks are compared to clarify which modulating effects of the 30-60-day ISO are exerted on TC movements.
During the period 1979-2015, modulating processes of the 30-60-day ISO on the migratory TCs vary in relation to the variability of the WPSH, MT, and ET in different months. The salient features of ISO modulation on TC movement are summarized in Fig. 14. In July and August (Fig. 14a), the dominant influential feature of the 30-60-day ISO is an anomalous anticyclone to the north of $20^{\circ} \mathrm{N}$ (denoted by "AC") accompanied by a westward intensification of the WPSH. Anomalous southeasterly flows in the southern peripheries of this anomalous anticyclone and the WPSH steer TCs northwestward toward the SCS. In September (Fig. 14b), the major 3060-day anomalies appear as a meridional circulation pair with an anomalous anticyclone to the north of $20^{\circ} \mathrm{N}$ and a zonally elongated anomalous cyclone to the south. This circulation pair is associated with a southeastward intensification of the MT. Strong anomalous southeasterly flows between the above circulation pair effectively guide TCs from the Philippine Sea into the SCS. In October and November (Fig. 14c), TCs tend to form in the eastern section of a 30-60-day cyclonic anomaly across the SCS and the tropical WNP and follow anomalous easterly flows in the northern section of this 

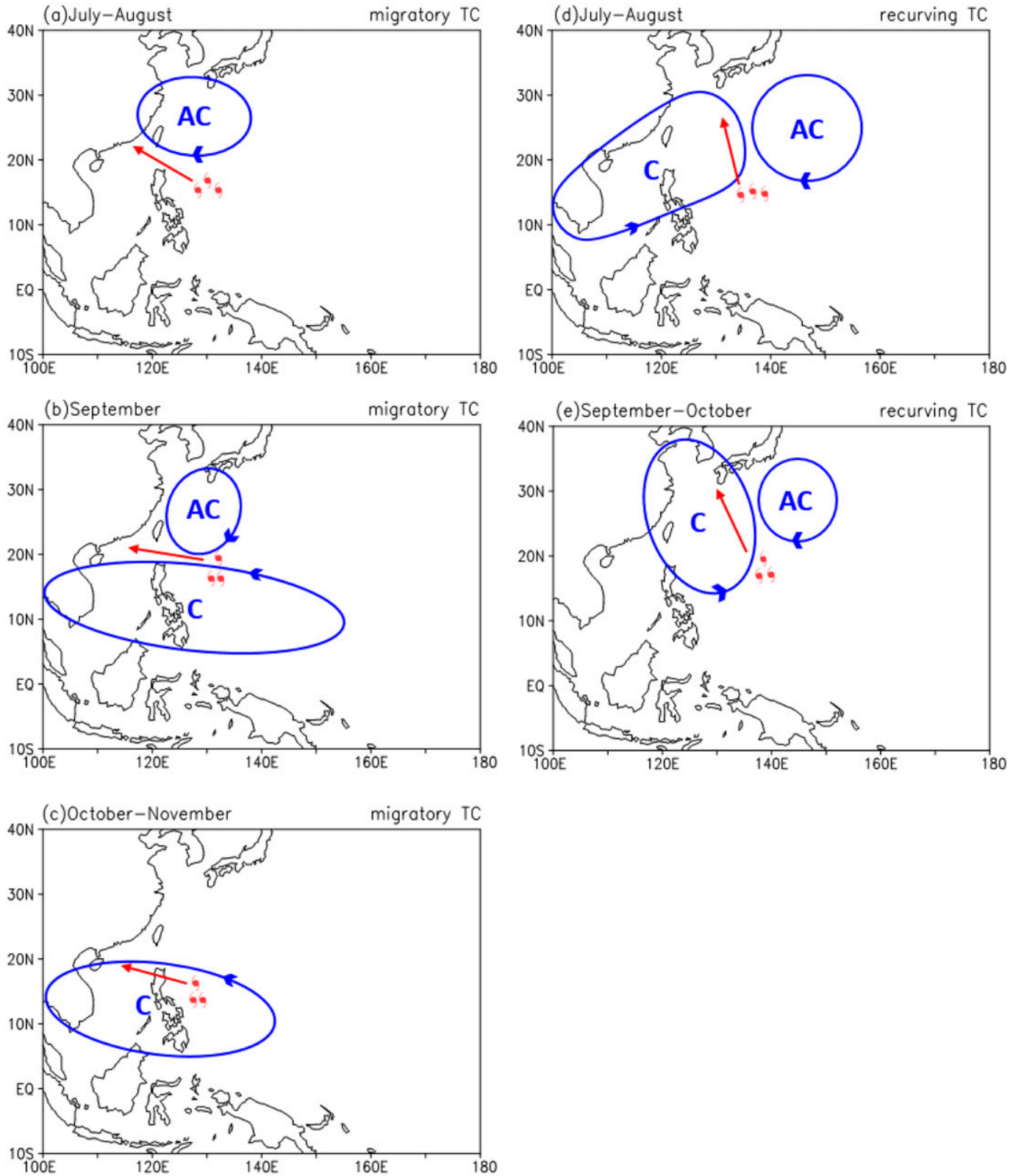

FIG. 14. Schematic diagrams for modulating processes exerted by the 30-60-day ISO circulations on movements of the migratory TCs in (a) July-August, (b) September, and (c) October-November and movements of the recurving TCs in (d) July-August and (e) September-October. An anomalous anticyclone is denoted by "AC" while an anomalous cyclone is denoted by "C". TCs are represented by red symbols. Arrows indicate TC movements.

cyclonic anomaly to move westward into the SCS. The 30-60-day anomalous cyclone coexists with an intensified ET.

Also shown in Fig. 14 are the modulating processes of the 30-60-day ISO on the recurving TCs. In July and August (Fig. 14d), the major 30-60-day anomalies modulating the recurving TCs appear as an east-west circulation pair with an anomalous cyclone extending from the SCS into Japan and an anomalous anticyclone on its east. TCs tend to form in a region south of or between this circulation pair and are steered by anomalous southerly/southeasterly flows to move northward. In September and October (Fig. 14e), the recurving TCs tend to form in the eastern/southeastern section of an anomalous cyclone with a center to the east of Taiwan. It is paired with an anomalous anticyclone on its east. These TCs are steered by anomalous southerly/southeasterly flows along the eastern section of the anomalous 
cyclone to move northward. These schematics clearly demonstrate that the 30-60-day ISO imposes different modulating processes to steer TCs along different tracks.

Our analyses have established the relationships between TC movement, ISO anomalies, and variability of the climatological circulations. The modulating processes of the 30-60-day ISO and climatological circulations on TC movements vary from month to month. The common ISO feature of the active TC season is having enhanced convective anomalies over the SCS and WNP prior to the arrival of the migratory TCs. These enhanced tropical convections and associated circulation variability provide favorable conditions for TC movement into the SCS. This study also demonstrates that the ISO anomalies and climatological circulations exhibit different modulating processes on different TC movements. Future variability of the WPSH, MT, and ET can be captured to some extent by current seasonal predictions. Variability features of these climatological circulations may be further applied to predict an increase or a decrease in the migratory and recurving TCs. For example, the zonal variability of the WPSH in July and August, the location of the intensifying center of the MT in September, and the direction of intensification of the ET in October and November can serve as useful monitoring indices to predict future TC movement in the tropical WNP and the SCS. Such prediction tools should provide useful information to improve seasonal predictions of TC activity in regions around the SCS and East Asia.

Acknowledgments. We thank the reviewers for their valuable comments to improve the quality of this paper. This study was supported by the Minister of Science and Technology, Taiwan, under grants of MOST 106-2111M-022-001-MY2, MOST 106-2111-M-002-003-MY2, and MOST 106-2111-M-845-002. Jianyun Gao was supported by the National Natural Science Foundation, China, under Grant 41575052.

\section{REFERENCES}

Aiyyer, A., A. Mekonnen, and C. J. Schreck, 2012: Projection of tropical cyclones on wavenumber-frequency-filtered equatorial waves. J. Climate, 25, 3653-3658, https://doi.org/10.1175/ JCLI-D-11-00451.1.

Barrett, B. S., and L. M. Leslie, 2009: Links between tropical cyclone activity and Madden-Julian oscillation phase in the North Atlantic and northeast Pacific basins. Mon. Wea. Rev., 137, 727-744, https://doi.org/10.1175/2008MWR2602.1.

Bi, M., T. Li, X. Shen, and M. Peng, 2015: To what extent the presence of real-strength tropical cyclones influences the estimation of atmospheric intraseasonal oscillation intensity? Atmos. Sci. Lett., 16, 438-444, https://doi.org/10.1002/asl.579.
Camargo, S. J., A. W. Robertson, S. J. Gaffney, P. Smyth, and M. Ghil, 2007: Cluster analysis of typhoon tracks: Part I: General properties. J. Climate, 20, 3635-3653, https://doi.org/ 10.1175/JCLI4188.1.

Chan, J. C. L., 2000: Tropical cyclone activity over the western North Pacific associated with El Niño and La Niña events. J. Climate, 13, 2960-2972, https://doi.org/10.1175/1520-0442(2000) 013<2960:TCAOTW>2.0.CO;2.

Chang, C. P., and G. T.-J. Chen, 1995: Tropical circulation associated with southwest monsoon onset and westerly surges over the South China Sea. Mon. Wea. Rev., 123, 3254-3267, https://doi.org/10.1175/1520-0493(1995)123<3254: TCAWSM $>2.0 . \mathrm{CO} ; 2$.

Chen, G. T.-J., 1994: Large-scale circulation associated with the East Asian summer monsoon and the mei-yu over South China and Taiwan. J. Meteor. Soc. Japan, 72, 959-983, https:// doi.org/10.2151/jmsj1965.72.6_959.

Chen, J.-M., P.-H. Tan, L. Wu, J.-S. Liu, and H.-S. Chen, 2017: Climatological analysis of passage-type tropical cyclones from the western North Pacific into the South China Sea. Terr. Atmos. Oceanic Sci., 28, 327-343, https://doi.org/10.3319/ TAO.2016.10.04.02.

— C.-H. Wu, P.-H. Chung, and C.-H. Sui, 2018a: Influence of intraseasonal-interannual oscillations on tropical cyclone genesis in the western North Pacific. J. Climate, 31, 4949-4961, https://doi.org/10.1175/JCLI-D-17-0601.1.

, P.-H. Tan, L. Wu, H.-S. Chen, J.-S. Liu, and C.-F. Shih, 2018b: Interannual variability of summer tropical cyclone rainfall in the western North Pacific depicted by CFSR and associated large-scale processes and ISO modulations. J. Climate, 31, 1771-1787, https://doi.org/10.1175/JCLI-D-16-0805.1.

Chen, T.-C., and J.-M. Chen, 1995: An observational study of the South China Sea monsoon during the 1979 summer: Onset and life cycle. Mon. Wea. Rev., 123, 2295-2318, https://doi.org/ 10.1175/1520-0493(1995)123<2295:AOSOTS > 2.0.CO;2.

—-, M.-C. Yen, and S.-P. Weng, 2000: Interaction between the summer monsoon in East Asia and the South China Sea: Intraseasonal monsoon mode. J. Atmos. Sci., 57, 1373-1392, https://doi.org/10.1175/1520-0469(2000)057<1373: IBTSMI $>2.0 . \mathrm{CO} ; 2$.

_ , S.-Y. Wang, and M.-C. Yen, 2006: Interannual variation of the tropical cyclone activity over the western North Pacific. J. Climate, 19, 5709-5720, https://doi.org/10.1175/ JCLI3934.1.

,,--- , and A. Clark, 2009: Impact of the intraseasonal variability of the western North Pacific large-scale circulation on tropical cyclone tracks. Wea. Forecasting, 24, 646-666, https://doi.org/10.1175/2008WAF2222186.1.

Choi, Y., and K.-J. Ha, 2018: Subseasonal shift in tropical cyclone genesis over the western North Pacific in 2013. Climate Dyn., 51, 4451-4467, https://doi.org/10.1007/s00382-017-3926-0.

Chu, P.-S., X. Zhao, C.-H. Ho, H.-S. Kim, M.-M. Lu, and J.-H. Kim, 2010: Bayesian forecasting of seasonal typhoon activity: A trackpattern-oriented categorization approach for Taiwan. J. Climate, 23, 6654-6668, https://doi.org/10.1175/2010JCLI3710.1.

Dee, D. P., and Coauthors, 2011: The ERA-Interim reanalysis: Configuration and performance of the data assimilation system. Quart. J. Roy. Meteor. Soc., 137, 553-597, https://doi.org/ 10.1002/qj.828.

Ding, Y. H., 1994: Monsoon over China. Kluwer Academic, 419 pp. , 2007: The variability of the Asian summer monsoon. J. Meteor. Soc. Japan, 85B, 21-54, https://doi.org/10.2151/ jmsj.85B.21. 
Duchon, C. E., 1979: Lanczos filtering in one and two dimensions. J. Appl. Meteor., 18, 1016-1022, https://doi.org/10.1175/15200450(1979)018<1016:LFIOAT $>2.0$. CO;2.

Feng, X., R. Wu, J. Chen, and Z. Wen, 2013: Factors for interannual variations of September-October rainfall in Hainan, China. J. Climate, 26, 8962-8978, https://doi.org/10.1175/JCLID-12-00728.1.

Gao, J., and T. Li, 2011: Factors controlling multiple tropical cyclone events in the western North Pacific. Mon. Wea. Rev., 139, 885-894, https://doi.org/10.1175/2010MWR3340.1.

—, and -2012 : Interannual variation of multiple tropical cyclone events in the western North Pacific. Adv. Atmos. Sci., 29, 1279-1291, https://doi.org/10.1007/s00376-012-1031-1.

Goh, A. Z.-C., and J. C. L. Chan, 2010: Interannual and interdecadal variations of tropical cyclone activity in the South China Sea. Int. J. Climatol., 30, 827-843, https://doi.org/10.1002/JOC.1943.

Hall, J. D., A. J. Matthews, and D. Karoly, 2001: The modulation of tropical cyclone activity in the Australian region by the Madden-Julian oscillation. Mon. Wea. Rev., 129, 2970-2982, https://doi.org/10.1175/1520-0493(2001)129<2970: TMOTCA $>2.0 . \mathrm{CO} ; 2$.

Harr, P. A., and R. L. Elsberry, 1991: Tropical cyclone track characteristics as a function of large-scale circulation anomalies. Mon. Wea. Rev., 119, 1448-1468, https://doi.org/10.1175/ 1520-0493(1991)119<1448:TCTCAA > 2.0.CO;2.

Hartmann, D. L., M. L. Michelsen, and S. A. Klein, 1992: Seasonal variations of tropical intraseasonal oscillations: A 2025-day oscillation in the western Pacific. J. Atmos. Sci., 49, 1277-1289, https://doi.org/10.1175/1520-0469(1992)049<1277: SVOTIO $>2.0 . \mathrm{CO} ; 2$.

Ho, C.-H., J.-J. Baik, J.-H. Kim, D.-Y. Gong, and C.-H. Sui, 2004: Interdecadal changes in summertime typhoon tracks. J. Climate, 17, 1767-1776, https://doi.org/10.1175/1520-0442(2004)017<1767: ICISTT $>2.0 . \mathrm{CO} ; 2$.

Hsu, H.-H., 2005: East Asian and western North Pacific summer monsoon region. Intraseasonal Variability in the AtmosphereOcean System, W. K. M. Lau and D. E. Waliser, Eds., Springer-Praxis, 65-98.

_ , and C.-H. Weng, 2001: Northwestward propagation of the intraseasonal oscillation in the western North Pacific during the boreal summer: Structure and mechanism. J. Climate, 14, 3834-3850, https://doi.org/10.1175/1520-0442(2001)014<3834: NPOTIO $>2.0 . \mathrm{CO} ; 2$.

- C.-H. Hung, A.-K. Lo, C.-C. Wu, and C.-W. Hung, 2008: Influence of tropical cyclones on the estimation of climate variability in the tropical western North Pacific. J. Climate, 21, 2960-2975, https://doi.org/10.1175/2007JCLI1847.1.

Hsu, P.-C., T. Li, and C.-H. Tsou, 2011: Interactions between boreal summer intraseasonal oscillations and synoptic-scale disturbances over the western North Pacific. Part I: Energetics diagnosis. J. Climate, 24, 927-941, https://doi.org/10.1175/ 2010JCLI3833.1.

Huang, P., C. Chou, and R. Huang, 2011: Seasonal modulation of tropical intraseasonal oscillations on tropical cyclone geneses in the western North Pacific. J. Climate, 24, 6339-6352, https:// doi.org/10.1175/2011JCLI4200.1.

Kim, J.-H., C.-H. Ho, H.-S. Kim, C.-H. Sui, and S. K. Park, 2008: Systematic variation of summertime tropical cyclone activity in the western North Pacific in relation to the Madden-Julian oscillation. J. Climate, 21, 1171-1191, https://doi.org/10.1175/ 2007JCLI1493.1.

Kim, J.-S., C.-Y. Li, and W. Zhou, 2012: Effects of the Pacific-Japan teleconnection pattern on tropical cyclone activity and extreme precipitation events over the Korean peninsula. J. Geophys. Res., 117, D18109, https://doi.org/10.1029/2012JD017677.

Klotzbach, P., 2014: The Madden-Julian oscillation's impacts on worldwide tropical cyclone activity. J. Climate, 27, 2317-2330, https://doi.org/10.1175/JCLI-D-13-00483.1.

Ko, K.-C., and H.-H. Hsu, 2006: Sub-monthly circulation features associated with tropical cyclone track over the East Asian monsoon area during July-August season. J. Meteor. Soc. Japan, 84, 871-889, https://doi.org/10.2151/jmsj.84.871.

_ and 2009: ISO modulation on the submonthly wave pattern and recurving tropical cyclones in the tropical western North Pacific. J. Climate, 22, 582-599, https://doi.org/10.1175/ 2008JCLI2282.1.

Lander, M., 1996: Specific tropical cyclone track types and unusual tropical cyclone motions associated with a reverse-oriented monsoon trough in the western North Pacific. Wea. Forecasting, 11, 170-186, https://doi.org/10.1175/1520-0434(1996) $011<0170:$ STCTTA $>2.0 . \mathrm{CO} ; 2$.

Li, R. C. Y., and W. Zhou, 2013: Modulation of western North Pacific tropical cyclone activity by the ISO. Part II: Tracks and landfall. J. Climate, 26, 2919-2930, https://doi.org/10.1175/ JCLI-D-12-00211.1.

, - _ J. C. L. Chan, and P. Huang, 2012: Asymmetric modulation of the western North Pacific cyclogenesis by the Madden-Julian oscillation under ENSO conditions. J. Climate, 25, 5374-5385, https://doi.org/10.1175/JCLI-D-1100337.1 .

, - - and T. Li, 2014: Influences of the Pacific-Japan teleconnection pattern on synoptic-scale variability in the western North Pacific. J. Climate, 27, 140-154, https://doi.org/10.1175/ JCLI-D-13-00183.1.

- — C. M. Shun, and T. C. Lee, 2017: Change in destructiveness of landfalling tropical cyclones over China in recent decades. J. Climate, 30, 3367-3379, https://doi.org/ 10.1175/JCLI-D-16-0258.1.

Li, T., and B. Wang, 2005: A review on the western North Pacific monsoon: Synoptic-to-interannual variabilities. Terr. Atmos. Oceanic Sci., 16, 285-314, https://doi.org/10.3319/ TAO.2005.16.2.285(A).

Liebmann, B., and C. A. Smith, 1996: Description of a complete (interpolated) outgoing longwave radiation dataset. Bull. Amer. Meteor. Soc., 77, 1275-1277.

,- H. H. Hendon, and J. D. Glick, 1994: The relationship between tropical cyclones of the western Pacific and Indian Oceans and the Madden-Julian oscillation. J. Meteor. Soc. Japan, 72, 401-412, https://doi.org/10.2151/jmsj1965.72.3_401.

Malkus, J. S., 1962: Large-scale interactions. The Sea: Ideas and Observations, Vol. 1, Interscience Publishers, 88-294.

Mao, J., and C. L. Chan, 2005: Intraseasonal variability of the South China Sea summer monsoon. J. Climate, 18, 2388-2402, https://doi.org/10.1175/JCLI3395.1.

Nakazawa, T., and K. Rajendran, 2007: Relationship between tropospheric circulation over the western North Pacific and tropical cyclone approach/landfall on Japan. J. Meteor. Soc. Japan, 85, 101-114, https://doi.org/10.2151/jmsj.85.101.

Su, O.-H., and F. Xue, 2011: Two northward jumps of the summertime western Pacific subtropical high and their associations with the tropical SST anomalies. Atmos. Oceanic Sci. Lett., 4, 98-102, https://doi.org/10.1080/16742834.2011.11446910.

Sui, C.-H., P.-H. Chung, and T. Li, 2007: Interannual and interdecadal variability of the summertime western North Pacific subtropical high. Geophys. Res. Lett., 34, L11701, https:// doi.org/10.1029/2006GL029204. 
Tan, P.-H., J.-Y. Tu, L. Wu, H.-S. Chen, and J.-M. Chen, 2019: Asymmetric relationships between El Niño-Southern Oscillation and entrance tropical cyclones in the South China Sea during fall. Int. J. Climatol., 39, 1872-1888, https://doi.org/10.1002/joc.5921.

Tsou, C.-H., P.-C. Hsu, W.-S. Kau, and H.-H. Hsu, 2005: Northward and northwestward propagation of 30-60 day oscillation in the tropical and extratropical western North Pacific. J. Meteor. Soc. Japan, 83, 711-726, https://doi.org/10.2151/jmsj.83.711.

Tu, J.-Y., and J.-M. Chen, 2019: Large-scale indices for assessing typhoon activity around Taiwan. Int. J. Climatol., 39, 921-933, https://doi.org/10.1002/joc.5852.

Wang, B., and Z. Fan, 1999: Choice of South Asian summer monsoon indices. Bull. Amer. Meteor. Soc., 80, 629-638, https://doi.org/ 10.1175/1520-0477(1999)080<0629:COSASM > 2.0.CO;2.

— , and LinHo, 2002: Rainy season of the Asian-Pacific summer monsoon. J. Climate, 15, 386-398, https://doi.org/10.1175/ 1520-0442(2002)015<0386:RSOTAP $>2.0$. CO;2.

Wang, G., J. Su, Y. Ding, and D. Chen, 2007: Tropical cyclone genesis over the South China Sea. J. Mar. Syst., 68, 318-326, https://doi.org/10.1016/j.jmarsys.2006.12.002.

Wheeler, M., and H. Hendon, 2004: An all-season real-time multivariate MJO index: Development of an index for monitoring and prediction. Mon. Wea. Rev., 132, 19171932, https://doi.org/10.1175/1520-0493(2004)132<1917: AARMMI $>2.0 . \mathrm{CO} ; 2$.

Wu, L., and C. Wang, 2015: Has the western Pacific subtropical high extended westward since the late 1970s? J. Climate, 28, 5406-5413, https://doi.org/10.1175/JCLI-D-14-00618.1.

—, and M. Takahashi, 2018: Contributions of tropical waves to tropical cyclone genesis over the western North Pacific. Climate Dyn., 50, 4635-4649, https://doi.org/10.1007/s00382-0173895-3.

_ , Z. Wen, R. Huang, and R. Wu, 2012: Possible linkage between the monsoon trough variability and the tropical cyclone activity over the western North Pacific. Mon. Wea. Rev., 140, 140-150, https://doi.org/10.1175/MWR-D 11-00078.1.

Wu, R., 2002: Processes for the northeastward advance of the summer monsoon over the western North Pacific. J. Meteor Soc. Japan, 80, 67-83, https://doi.org/10.2151/jmsj.80.67.

Zhou, H., P.-C. Hsu, and Y. Qian, 2018: Close linkage between quasi-biweekly oscillation and tropical cyclone intensification over the western North Pacific. Atmos. Sci. Lett., 19, e826, https://doi.org/10.1002/asl.826. 